\title{
Hydroxylated boron nitride materials: from structures to functional applications
}

\author{
Junkai Ren ${ }^{1}$, Luigi Stagi ${ }^{1, *}$ (D), and Plinio Innocenzi ${ }^{1, \star}$ \\ ${ }^{1}$ Laboratory of Materials Science and Nanotechnology (LMNT), CR-INSTM, Department of Chemistry and Pharmacy, University of \\ Sassari, Via Vienna, 2, 07100 Sassari, Italy
}

Received: 25 September 2020

Accepted: 27 October 2020

Published online:

12 November 2020

(C) The Author(s) 2020

\begin{abstract}
Functionalization of boron nitride (BN) materials with hydroxyls has attracted great attention to accomplish better performances at micro- and nanoscale. BN surface hydroxylation, in fact, induces a change in properties and allows expanding the fields of application. In this review, we have summarized the state-of-the-art in developing hydroxylated bulk and nanoscale BN materials. The different synthesis routes to develop hydroxyl BN have been critically discussed. What emerges is the great variety of possible strategies to achieve BN hydroxylation, which, in turn, represents one of the most suitable methods to improve the solubility of BN nanomaterials. The improved stability of BN solutions creates conditions for producing high-quality nanocomposites. Furthermore, new interesting optical and electronic properties may arise from the functionalization by $\mathrm{OH}$ groups as displayed by a wide range of both theoretical and experimental studies. After the presentation of the most significant systems and methodologies, we question of future perspective and important trends of the next generation $\mathrm{BN}$ materials as well as the possible areas of advanced research.
\end{abstract}

Handling Editor: Catalin Croitoru.

Address correspondence to E-mail: lstagi@uniss.it; plinio@uniss.it 


\section{GRAPHICAL ABSTRACT}

Hydroxyl functionalization of boron nitride materials is a key method to control and enhance the properties and design new functional applications.

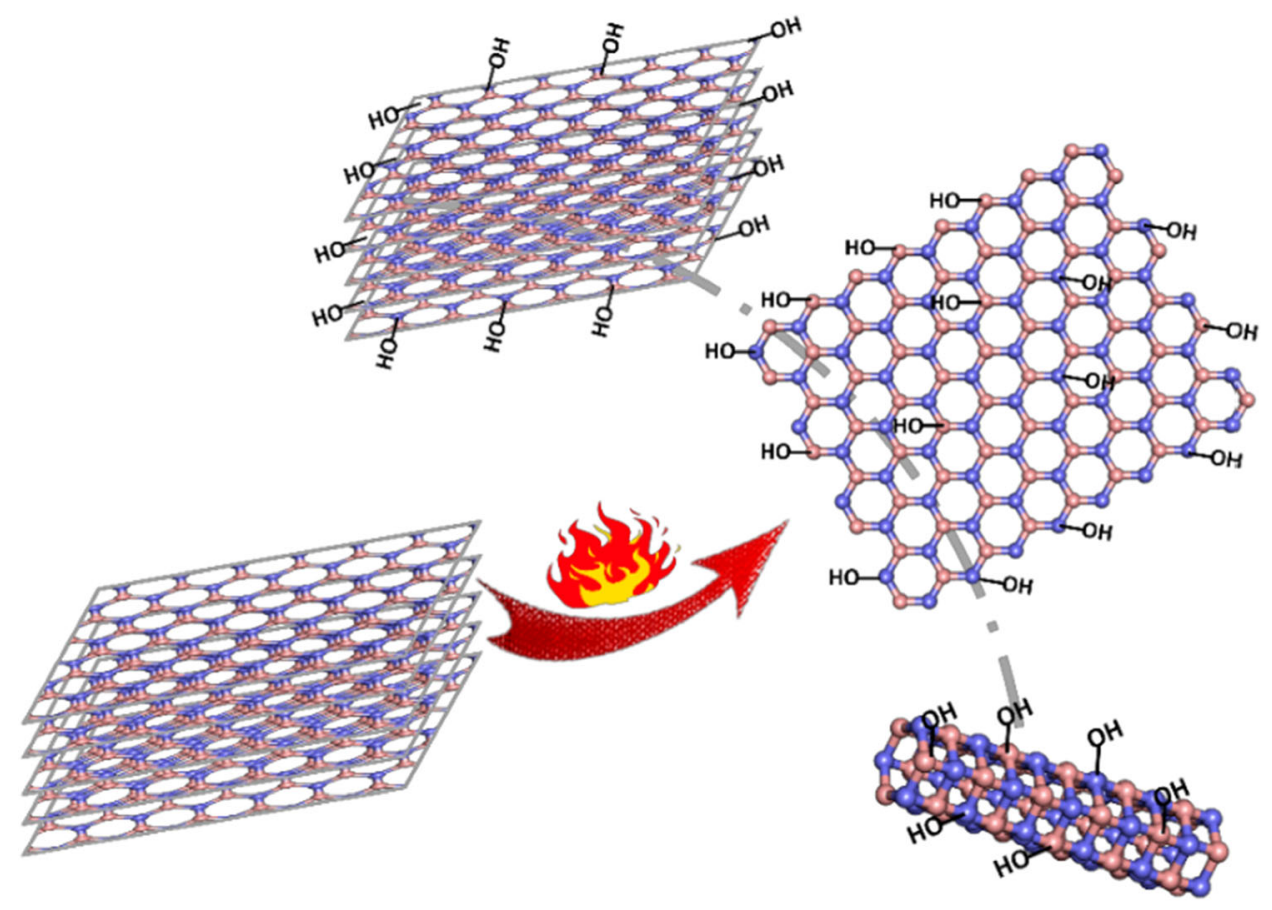

Abbreviations

$\mathrm{BN}$

Boron nitride

$h_{-}, c^{-}, r_{-}^{-}, w_{-}^{-}$

NS

NR

NT

ICTES

APTES

PS

PP

P2VP

PNBMT

MPTMS

SPEEK

PFOS

PFDA

DMSO wurtzite

Nanosheet

Nanoribbon

Nanotube

Polystyrene
Hexagonal, cubic, rhombohedral,

(3-Isocyanatopropyl) triethoxysilane

3-Aminopropyltriethoxysilane

Polypropylene

Poly(2-vinylpyridine)

Poly(5-norbornene-2-methanol)

(3-Mercaptopropyl) trimethoxysilane

Sulfonated poly (ether ether ketone)

Perfluorooctanesulfonate

Perfluorodecanoate

Dimethyl sulfoxide
NMP N-methyl-2-pyrrolidone

PAI Polyamide-imide

PVA Polyvinyl alcohol

NLO Nonlinear optics

OL Optical limiting

EELS Electron energy loss spectroscopy

PNIPAM Poly(N-isopropylalacrylamide)

SDS Sodium dodecyl sulfate

TBP Di-tert-butylperoxide

PVDF Poly(vinylidene fluoride)

CVD Chemical vapor deposition

PC Polycarbonate

DFT Density functional theory

MD Molecular dynamics

GGA Generalized gradient approximation

DNP Double numerical basis sets plus polarization function

CASTEP Cambridge Serial Total Energy Package

DOX Doxorubicin hydrochloride 


\section{Introduction}

The remarkable properties exhibited by boron nitride-based (BN) nanomaterials have attracted much attention and have risen the expectations of new breakthrough applications. Structurally similar to carbon system, BNs exist in four different polymorphs: graphite-like hexagonal $\mathrm{BN}(h-\mathrm{BN})$ and rhombohedral $(r$-BN), diamond-like cubic BN $(c-\mathrm{BN})$ and wurtzite $\mathrm{BN}(w$-BN) $[1,2]$. Among them, $h$-BN has shown excellent properties, such as outstanding mechanical strength, high thermal conductivity, and excellent lubrication. 2D $h$-BN has a layered structure similar to graphene (see Fig. 1a). Graphene is a kind of honeycomb crystals with $\mathrm{sp}^{2}$ hybridized carbon atoms, and the hexagonal geometry endows it with a very stable structure. An equal number of $\mathrm{B}$ and $\mathrm{N}$ atoms forms the $h$-BN layer, where the $\mathrm{sp}^{2}$ covalent bond links alternating $\mathrm{B}$ and $\mathrm{N}$ atoms. Weak Van der Waals bonds between different planes keep together the $h$-BN 2D layers, similarly to graphite; however, the $\mathrm{B}-\mathrm{N}$ bond has a slight ionic character in comparison with the covalent $\mathrm{C}-\mathrm{C}$ bond of graphite.

The $h$-BNs unique structural characteristics are also reflected in the electrical and optical properties [3-6]. For instance, $h$-BN presents a wide bandgap $\left(E_{g}\right)$ value, around $6 \mathrm{eV}$, confirmed by both theoretical and experimental works $[7,8]$. As in the case of carbon nanomaterials, which includes carbon nanotubes

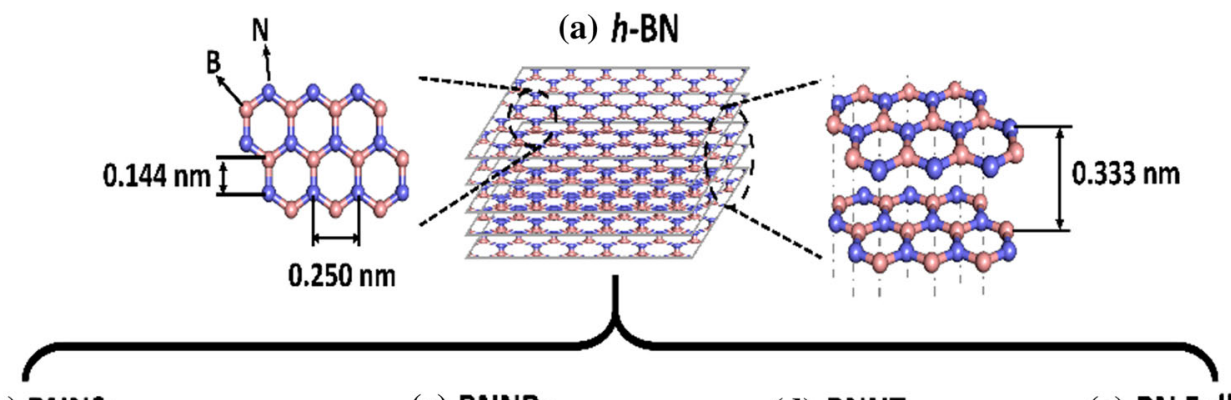

(b) BNNSs
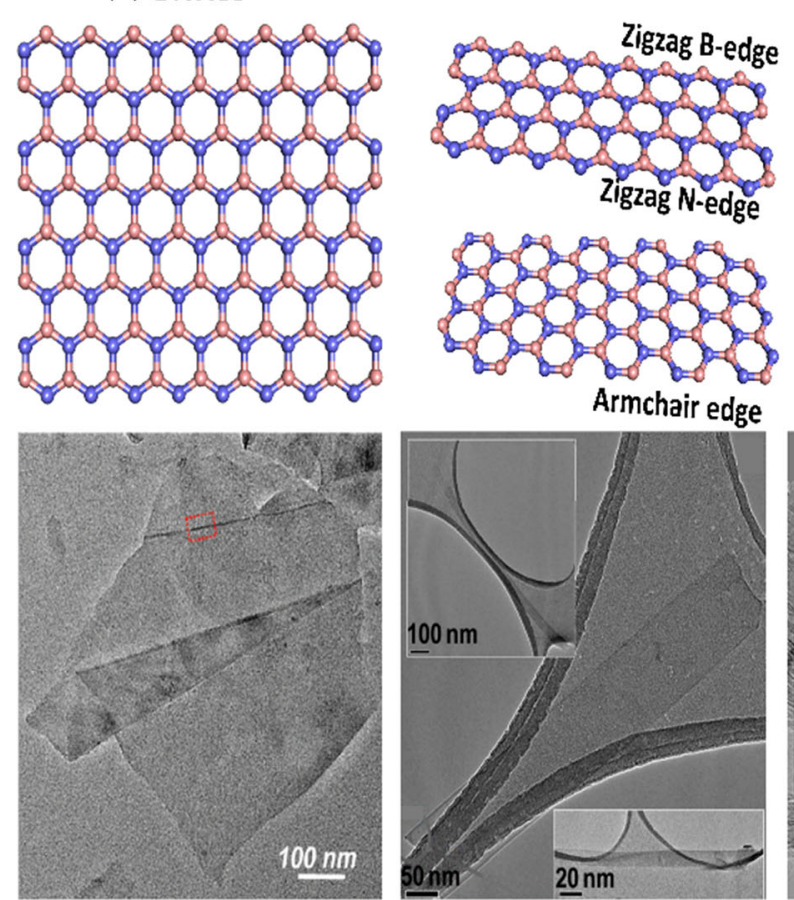

Armchair edge

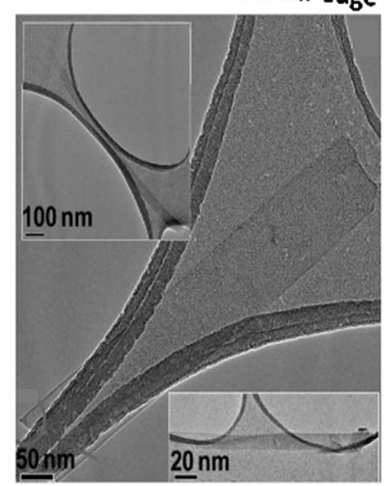

(d) BNNTs
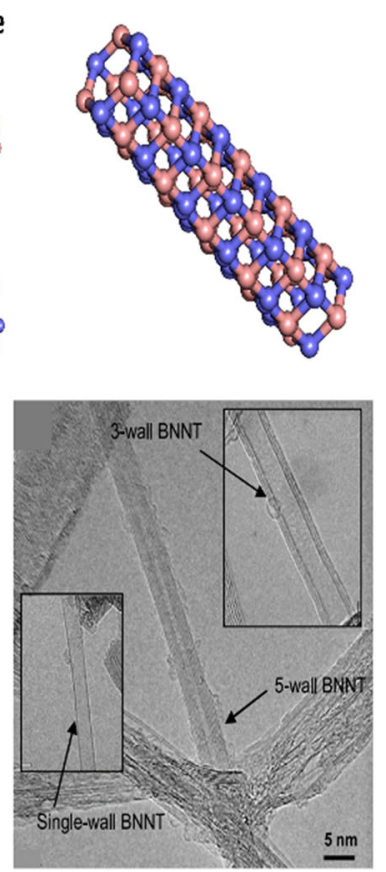

(e) BN Fullerenes
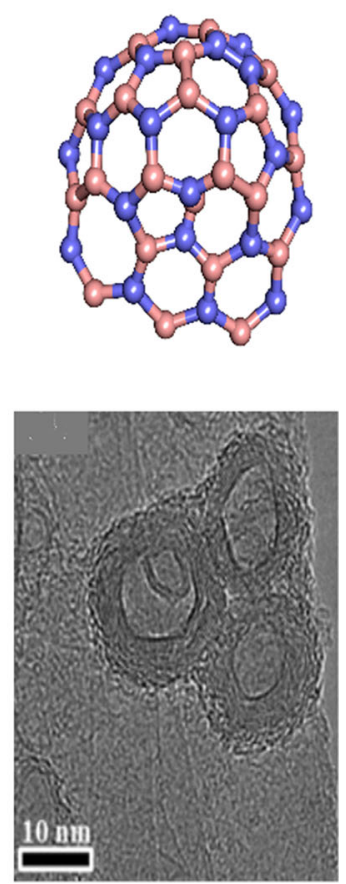

Figure 1 Structural models of $h$-BN crystal and four typical $\mathrm{BN}$ nanomaterials: a $h$-BN structure and some basic parameters, b BNNSs, c BNNRs, d BNNTs, and e BN fullerenes. The relevant TEM images are shown on the bottom, reproduced from Refs.
[11-14] with permissions of Copyright (2010) American Chemical Society, Copyright (2014) American Chemical Society, Copyright (2009) Institute of Physics, and Copyright (2015) Springer. 
Figure 2 a The number of publications based on $\mathrm{BN}$ research from 2000 to 2019 ; b The percentage of publications based on different types of BN materials in 2019. ( Source of data: Web of Science with "boron nitride" as the keyword, searched in September 2020).

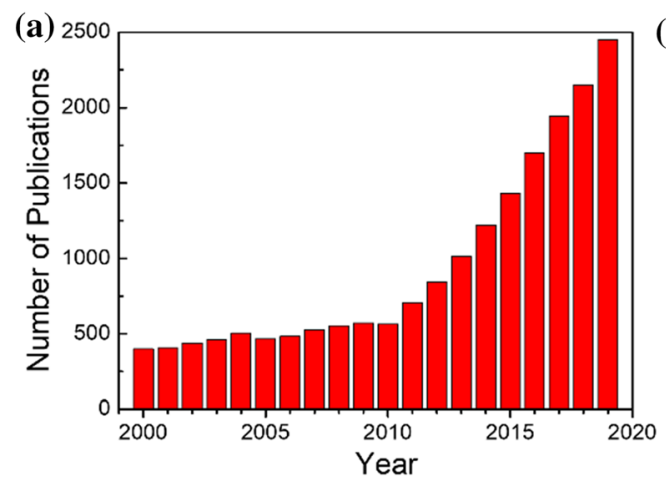

(b) $22.44 \%$ nanotubes

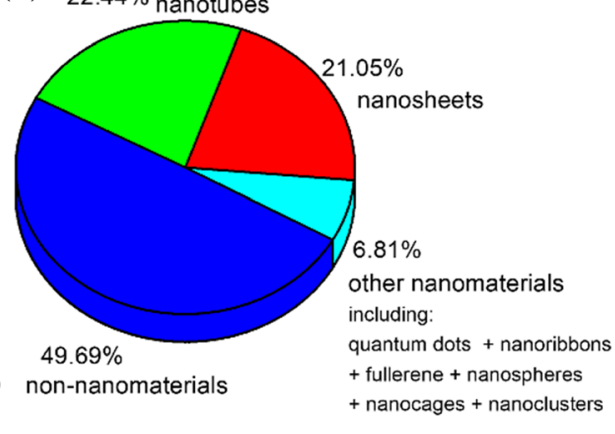

and graphene quantum dots, the layered structure of $h$-BN is also flexible enough to form many nanostructures [9, 10], as shown in Fig. 1b-e. In fact, there are BN nanosheets (BNNSs, also indicated as white graphene) [11], BN nanoribbons (BNNRs) [12], BN nanotubes (BNNTs) [13], BN fullerenes and cages [14], etc.

The number of publications on $\mathrm{BN}$-materials has dramatically increased in the past ten years (see Fig. 2a). Figure $2 \mathrm{~b}$ shows the publishing situation of BN materials in 2019: about 50\% regards nanomaterials, with research on both BNNTs and BNNSs accounting for nearly 20\%. According to these reports, BN systems are promising candidates as optoelectronic devices [15, 16], quantum emitters [17, 18], semiconductors [19], energy storage [20], thermal conductors [21], cosmetic products [22], water cleaning [23, 24], photocatalytic [25], as well as biomedical science [26], etc.

BN systems for functional applications require advanced synthesis and processing routes [27]. Nanomaterials are strongly dependent on their surface, and the functionalization methods are the key to design the desired properties. This becomes particularly important in 2D nanomaterials whose integration into devices and tailoring of properties are controlled via surface modification. In the case of $\mathrm{BNs}$, some functional strategies have been realized to modify their surface, including hydroxyl $(-\mathrm{OH})$, alkoxy (-OR), amino $\left(-\mathrm{NH}_{2}\right)$, and alkyl (-R) groups $[1,28,29]$. Compared with other surface functionalization, hydroxylation is the most important functionalization route for modifications of $\mathrm{BN}$ materials. Firstly, $-\mathrm{OH}$ groups are usually covalently attached to $\mathrm{B}$ sites in BN net-structure, whose introduction is easy and efficient to carry out, such as, by direct thermal oxidation of $h-\mathrm{BN}$ in the air [30], and sonication in $\mathrm{H}_{2} \mathrm{O}$ [31]. Importantly, hydroxyl groups have been applied as an intermediary bridge to realize further functionalization. For example, $-\mathrm{OH}$ on BN surface can react with organically modified alkoxides to obtain organosilane-functionalized BNs [32]. On the other hand, $-\mathrm{OH}$ groups in $\mathrm{BN}$ materials can react with $-\mathrm{COOH}$ of perfluoro butyric acid $\left(\mathrm{CF}_{3} \mathrm{CF}_{2} \mathrm{CF}_{2} \mathrm{COOH}\right)$ or thioglycolic acid $\left(\mathrm{HSCH}_{2}\right.$ $\mathrm{COOH}$ ) to prepared esterified (-OCOR) BNs [33].

Currently, surface hydroxylation has shown to be a flexible technique to change the chemical characteristics of BNs, which will further affect their physical features and mechanical properties. Hydroxylated BNs exhibit enhanced and innovative properties, either physical or chemical, in comparison with pristine systems. In particular, the introduction of hydroxyl groups allows homogeneous dispersion of $\mathrm{BN}$ materials in several solvents, facilitating the incorporation into matrixes, such as polymers and sol-gel systems. This is a key point for integrating $\mathrm{BN}$ nanomaterials into a solid-state device.

We have focused this review on the hydroxylated process of BN systems, from structure to applications. The surface hydroxylation has been analyzed both theoretically and experimentally. The current experimental strategies to achieve $\mathrm{OH}$ groups on bulk and nanoscale BNs surfaces have been critically revised, focusing on the change of properties caused by the functionalization.

\section{Hydroxylated BN micron-scale materials}

\section{Direct hydroxyl-modification of BNs}

The hydroxylation of $h$-BNs on micron scale is an important process for the development of commercial materials, and several strategies have been developed so far. A direct route to form hydroxyl species on the 


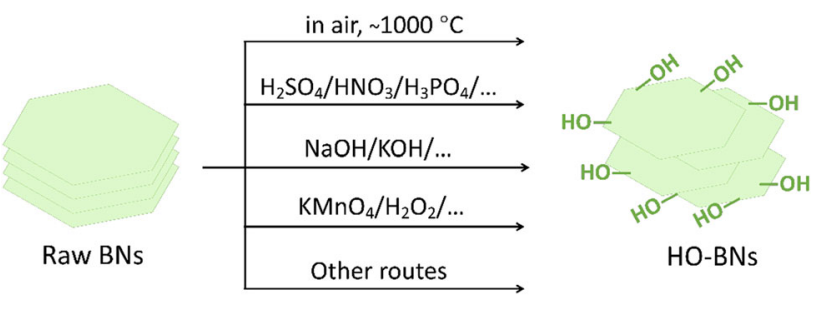

Figure 3 Different routes to hydroxyl-functionalize raw BNs.

$h$-BN surface is the treatment of powders in air at high temperature or in solution with the presence of strong acids, alkali, and oxidants agents (Fig. 3).

The simplest and most direct way to obtain $h$-BNs functionalized with $-\mathrm{OH}$ is heating the raw material in air, e.g., $1000{ }^{\circ} \mathrm{C}$ for $2 \mathrm{~h}[30,34,35]$. The hydroxyl groups allow a further $\mathrm{BNs}$ functionalization. For instance, BN/epoxy resin nanocomposites can be prepared via a sol-gel method using (3-isocyanatopropyl)triethoxysilane (ICTES) as a cross-linker, which enhances the thermal-oxidative stability [30]. Herein, the reaction between organosilane and $-\mathrm{OH}$ groups on $h$-BN surface permits a uniform dispersion of the particles into an epoxy resin. Another example is the modification of hydroxyl-activated $\mathrm{BNs}$ by 3-aminopropyltriethoxysilane (APTES) [35]. A BNpolystyrene (PS) composite has been obtained by in situ polymerization of styrene with the presence of APTES-BNs. By mixing BN-PS, PS and polypropylene (PP), ternary composites have been fabricated as BN-PS/(PP/PS). The thermal conductivity of the ternary composites is twice higher than naked PP and $30 \%$ higher than PP/BN composites.

For increasing the hydroxylation, pre-treatment of $\mathrm{BN}$ in a hot acidic solution, such as concentrated $\mathrm{HNO}_{3}$ [32], $\mathrm{H}_{2} \mathrm{SO}_{4}$ [36], and mixed acids, is a good choice $[37,38]$. HO-BNs can be prepared by sonicating $\mathrm{BNs}$ in $\mathrm{HNO}_{3}$ and $\mathrm{H}_{2} \mathrm{SO}_{4}$ (volume ratio = 3:1) mixed solutions (Fig. 4) [37]. The HO-BNs could form covalent composites with poly(2-vinylpyridine) (P2VP) and poly(5-norbornene-2-methanol) (PNBMT) via hydrogen bonding interactions and etherification reaction, respectively, with $-\mathrm{OH}$ groups. Ternary BN/P2VP/PNBMT composites have been obtained by self-assembly of BN/P2VP and BN/PNBMT; they exhibit dense packing, lower surface area, and higher density. These properties are attributed to the participation in cross-linking and the curing reaction by $\mathrm{OH}$ on BNs. Additionally, $\mathrm{NH}_{2}$ groups can be introduced through the reaction between HO-BNs and APTES. The product has also been self-assembled with graphene oxide under electrostatic interaction [32].

Another route to hydroxylate $h-\mathrm{BN}$ materials is pre-treatment of $\mathrm{BN}$ in a basic solution by a combination of stirring and heating [39-43]. In detail, hydroxyl-functional $\mathrm{BNs}$ are obtained by grafting organosilane coupling agents, which is a facile way to decrease the interface thermal resistance [39-41]. The organosilane-BNs have been embedded into some polymeric matrixes, such as epoxy [39, 40] and polyurethane acrylate [41], resulting in an improved thermal conductivity and long-term stability. The hydroxyl groups on BNs can further form hydrogen bonding with PVA chains, and, in this way, HO-BN/ lignin/PVA composite films can be prepared [42]. The composite has shown enhanced thermal conductivity, flame-retardancy capability, and mechanical flexibility.

Oxidants have also been employed to oxidize and functionalize $h$-BN with $\mathrm{OH}$ groups, including $\mathrm{H}_{2} \mathrm{O}_{2}$ [44, 45] and $\mathrm{KMnO}_{4}$ [45]. A hydrothermal method with $30 \% \mathrm{H}_{2} \mathrm{O}_{2}$ was used to modify the surface of $\mathrm{BNs}$, which not only increases hydroxyl percentage on $\mathrm{BN}$ but also introduces some boron and oxygen bondings [44]. To better hydroxylate $\mathrm{BN}$, [45] combination of oxidants and acids, including $\mathrm{H}_{2} \mathrm{SO}_{4}$, $\mathrm{H}_{3} \mathrm{PO}_{4}, \mathrm{KMnO}_{4}$, and $\mathrm{H}_{2} \mathrm{O}_{2}$, has been employed. After modification by (3-mercaptopropyl)trimethoxysilane (MPTMS), the prepared BN uniformly dispersed in sulfonated poly (ether ether ketone) (SPEEK) to form composite membranes. The membranes show high proton conductivity, low methanol crossover, and high selectivity. These proton exchange membranes can be used to develop direct methanol fuel cells.

Some other approaches have also been used for $h$ BNs hydroxylation. For example, hydroxyl-functionalized BNs have been obtained by ball milling of $h$ $\mathrm{BN}$ and sucrose [46]. The resulted carbonized BN/ lignosulfonate/rubber composites show excellent electrical and mechanical performances, which can be used for producing thermal interfacial management devices.

\section{Bottom-up ways for hydroxylated BNs}

Bottom-up synthesis routes are also popular for the preparation of hydroxylated BNs. As summarized in Table 1, the resulted products can be divided into two categories: (i) HO-BNs directly obtained via heating temperature in the range of $850-1100{ }^{\circ} \mathrm{C}$ [47-51]; (ii) 


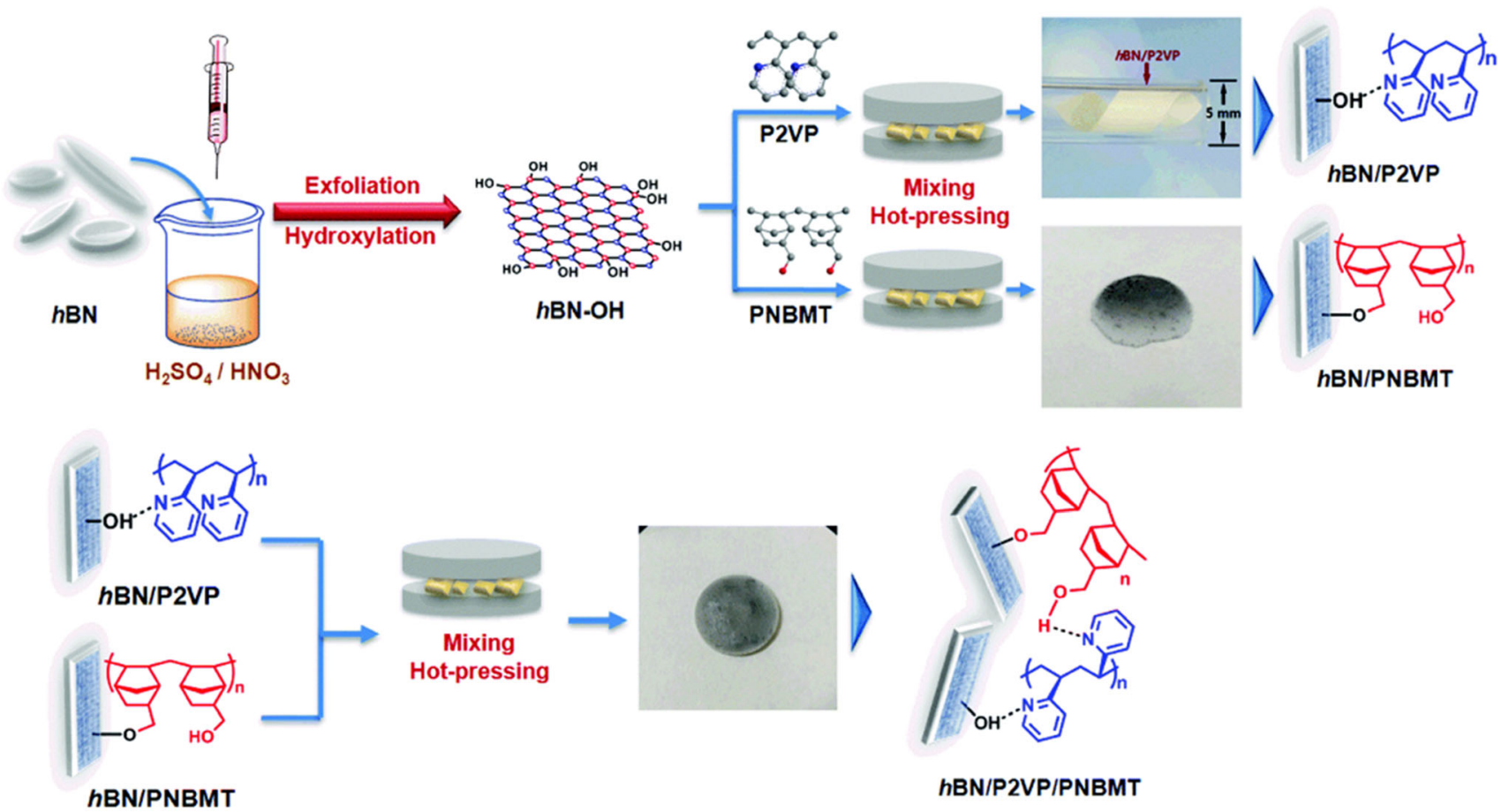

Figure 4 Diagram of the fabrication of BN/P2VP/PNBMT composites. Reproduced from Ref. [37] with permission of Copyright (2019) The Royal Society of Chemistry.

Table 1 A summary of bottom-up methods to prepare hydroxylated BNs

\begin{tabular}{|c|c|c|c|}
\hline Raw materials & Preparation method & Hydroxylation & Refs. \\
\hline Boric acid $(\mathrm{B})$, urea $(\mathrm{N})$ & Heating in $\mathrm{N}_{2}$ at $900{ }^{\circ} \mathrm{C}$ for $8 \mathrm{~h}$ & In situ & {$[47]$} \\
\hline Boric acid $(\mathrm{B})$, urea $(\mathrm{N})$ & $\begin{array}{l}\text { Heating in } \mathrm{N}_{2} \text { at } 850{ }^{\circ} \mathrm{C} \text { for } 16 \mathrm{~h} \text { and in air at } \\
600{ }^{\circ} \mathrm{C} \text { for } 2 \mathrm{~h}\end{array}$ & In situ & {$[48]$} \\
\hline $\begin{array}{l}\text { Boric acid (B), melamine } \\
(\mathrm{N})\end{array}$ & Heating under $\mathrm{N}_{2}$ flow at $1050{ }^{\circ} \mathrm{C}$ for $6 \mathrm{~h}$ & In situ & {$[49]$} \\
\hline $\begin{array}{l}\text { Boric acid (B), melamine } \\
(\mathrm{N})\end{array}$ & Heating in $\mathrm{N}_{2}$ at $1100^{\circ} \mathrm{C}$ for $1 \mathrm{~h}$ & In situ & {$[50]$} \\
\hline Boric acid $(\mathrm{B})$, urea $(\mathrm{N})$ & Heating at $1000{ }^{\circ} \mathrm{C}$ for $2 \mathrm{~h}$ & In situ & {$[51]$} \\
\hline $\begin{array}{l}\text { Boric acid (B), melamine } \\
(\mathrm{N})\end{array}$ & $\begin{array}{l}\text { Heating under } \mathrm{NH}_{3} \text { flow at } 546{ }^{\circ} \mathrm{C} \text { for } 2 \mathrm{~h} \\
\text { and } 1560{ }^{\circ} \mathrm{C} \text { for } 4 \mathrm{~h}\end{array}$ & Heating in $\mathrm{H}_{2} \mathrm{SO}_{4}$ and $\mathrm{HNO}_{3}$ at $80{ }^{\circ} \mathrm{C}$ for $2 \mathrm{~h}$ & {$[52]$} \\
\hline $\begin{array}{l}\text { Boric acid }(\mathrm{B}), \text { melamine } \\
\& \text { urea }(\mathrm{N})\end{array}$ & Heating under $\mathrm{N}_{2}$ flow at $1500{ }^{\circ} \mathrm{C}$ for $1 \mathrm{~h}$ & $\begin{array}{l}\text { Heating in air at } 560{ }^{\circ} \mathrm{C} \text { for } 1 \mathrm{~h} \text { and in } 5 \text { vol. } \% \mathrm{H}_{2} \mathrm{O} / \\
\mathrm{N}_{2} \text { at } 530{ }^{\circ} \mathrm{C} \text { for } 3 \mathrm{~h}\end{array}$ & {$[53]$} \\
\hline
\end{tabular}

$h$-BNs hydroxylated via post-processing at the temperature of $1500{ }^{\circ} \mathrm{C}[52,53]$.

In situ hydroxylation has been achieved using $\mathrm{H}_{3} \mathrm{BO}_{3}$ and urea as raw materials and applying a thermal treatment at $900{ }^{\circ} \mathrm{C}$ in $\mathrm{N}_{2}$ atmosphere [47]. The obtained $\mathrm{HO}-\mathrm{BNs}$ have been tested to remove perfluorooctanesulfonate (PFOS) and perfluorodecanoate (PFDA). Addition of $\mathrm{Ca}^{2+}$ causes a significant increase in the removal effect because of enhanced electrostatic interactions.

$\mathrm{H}_{3} \mathrm{BO}_{3}$ has been also combined with melamine to prepare $h$-BN fibers by heating at $1560{ }^{\circ} \mathrm{C}$ under $\mathrm{NH}_{3}$ flow, following hydroxy-functionalization by acidic treatment [52]. The resulting $\mathrm{HO}-\mathrm{BNs}$ exhibit an enhanced removal performance compared with pristine $h$-BNs, that has been tested in methylene blue degradation. 


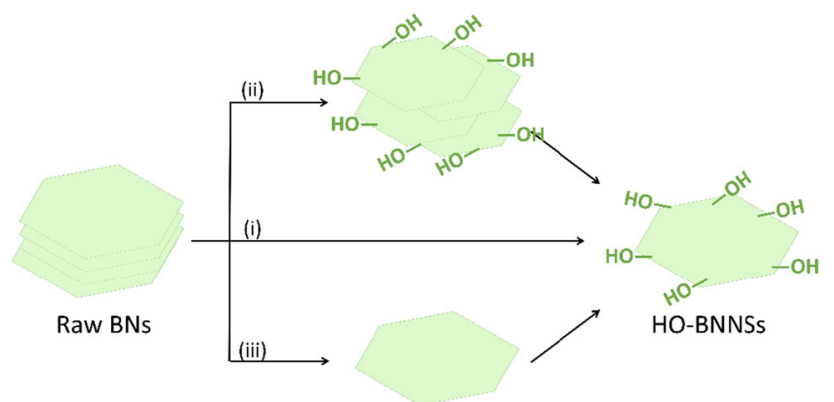

Figure 5 Top-down routes to hydroxyl-functionalize BNNSs.

\section{Hydroxylated BNNSs}

\section{Top-down routes for producing hydroxylated BNNSs}

2D $h$-BN sheets represent a very important family of $\mathrm{BN}$ materials. Top-down routes can be divided into three main types, as shown in Fig. 5: (i) HO-BNNSs are obtained by simultaneous exfoliation and functionalization of bulk $h$-BN; (ii) $h$-BNs are firstly hydroxylated and then HO-BNs are exfoliated into nanosheets; (iii) $h$-BNNSs are prepared by the exfoliation of BNs, and then functionalized with hydroxyl groups.

\section{One-pot sonication-assisted exfoliation}

$h$-BNs, hydroxylated nanosheets can be directly prepared by thermal oxidation of BNs in air, typically at $1000{ }^{\circ} \mathrm{C}$, followed by treatment in water [54]. Another simple way to obtain HO-BNNSs is to exfoliate $h$-BNs using water as dispersant solvent by sonication without any additional use of surfactants or organic functionalization [31, 55-59]. Sonication process can provide an intensive longitudinal shear force leading to complete exfoliation of the bulk into $h$-BNNSs with few layers and reduced lateral sizes, with attached $\mathrm{OH}$ groups (Fig. 6) [31]. HO-BNNSs are partially oxidized in the hydrolysis process [57] and show strong affinity toward proteins by Lewis acid-base interactions, confirming that surface-organic-free BNNSs have a high potential in biological applications.

Very recently, our research group has found that HO-BNNSs possess a weak photoluminescent emission in a visible range, centered at $\sim 400 \mathrm{~nm}$ [58]. Tailored defects can be further introduced through thermal treatment in air, and a maximum emissive intensity is achieved at $300{ }^{\circ} \mathrm{C}$ due to the role of hydroxyl groups created by the oxidation process (see Fig. 7). Subsequently, a higher temperature treatment $\left(500\right.$ or $700{ }^{\circ} \mathrm{C}$ ) causes a continuous fluorescent quenching. Notably, only bulk $h$-BNs exfoliated in water allow introducing $-\mathrm{OH}$ groups with the consequent emission. For instance, defect-free BNNSs are obtained when sonication is carried out in dimethyl sulfoxide (DMSO) or N-methyl-2-pyrrolidone (NMP), but they do not exhibit any fluorescence.

Various additives have already been investigated to enhance the hydrolyzation via sonication-assisted exfoliation. Addition of $\mathrm{HNO}_{3}$ [60], $\mathrm{NaOH}$ [61], sodium cholate [62], and plant extracts [63] is one of the most efficient strategies. As-prepared HO-BNNSs obtained by a tip-type sonication process under the assistance of sodium cholate can be easily incorporated into thermoplastic polyamide-imide (PAI) in the presence of polyvinyl alcohol (PVA) [62]. The hydrogen-bonded cross-linking networks between BNNSs and the polymer lead to 3D BN-composites, showing a thermal conductivity enhancement of 409\%. More recently, it has been demonstrated the efficacy of extracts of natural plants which work as ecofriendly surfactant agents and improve the exfoliation of $h$-BN into few-layer nanosheets under sonication. The obtained BNNSs result covered by abundant phytochemicals with $\mathrm{OH}$ groups [63].

\section{One-pot ball-milling-assisted exfoliation}

Ball-milling method realizes the exfoliation by the mechanical interaction between balls and $h$-BNs. The collision of the ball with the flank face of BN can make it to wrinkle and exfoliate (Fig. 8). Besides, as seen in the previous section, the introduction of some chemical agents, such as $\mathrm{NaOH}$ and $\mathrm{KOH}$ [64-67], $\mathrm{NaClO}$ [68], urea [69, 70], $\mathrm{H}_{3} \mathrm{BO}_{3}$ [71], and $\beta$-cyclodextrin [72], can lead to a synergetic effect of mechanical process and chemical peeling.

$\mathrm{NaOH}$-assisted ball milling process has been used to prepare HO-BNNSs with a yields of $\sim 18 \%$ through a simultaneously exfoliation and functionalization process [64]. The $\mathrm{NaOH}$ solution is not only used to promote the shear-force exfoliation, but also to functionalize the sheets via reaction of $h$-BN and $\mathrm{OH}$ radicals, leading to a high oxygen content of around 6.4 at\%. Liu et al. [67] reported a kind of nanohybrids composed of BNNSs and gold 
Figure 6 A scheme on exfoliation of $h$-BNs into HOBNNSs by sonication-assisted hydrolysis. Reproduced from Ref. [31] with permission of Copyright (2011) American Chemical Society.

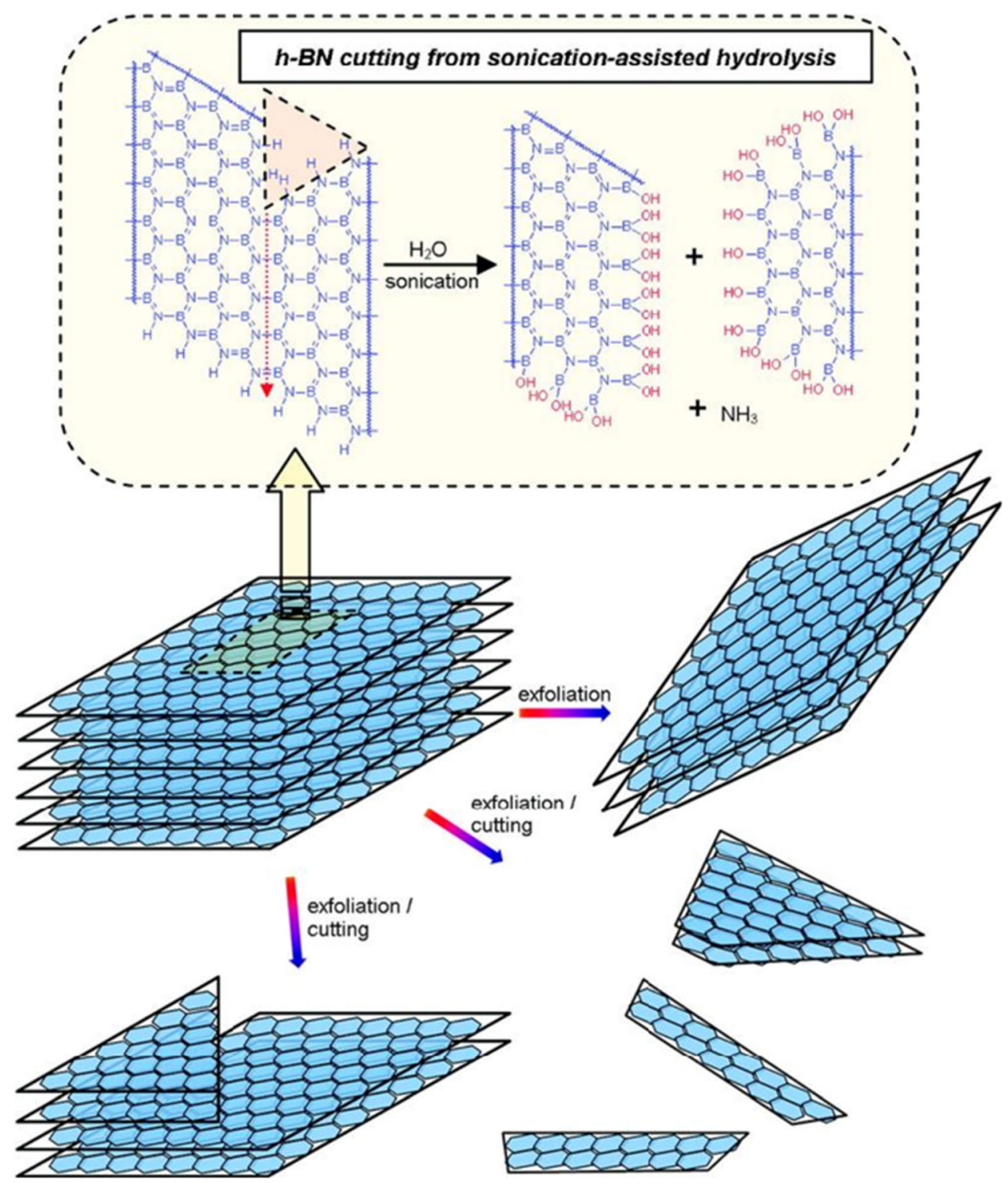

nanoclusters, where the ball-milling technique has been used to prepare BNNSs in the presence of mixed $\mathrm{NaOH}$ and $\mathrm{KOH}$. The nanohybrids can prevent aggregation of nanoclusters and exhibit a better catalytic activity for reducing 4-nitrophenol.

$h$-BNs can be functionalized by both $-\mathrm{OH}$ and $\mathrm{NH}_{2}$ by adding urea [69] or $\mathrm{H}_{3} \mathrm{BO}_{3}$ into the ballmilling system [71]. A nanocomposite membrane can be fabricated by embedding the obtained $h$-BNNSs into thermally rearranged polyimide for $\mathrm{H}_{2}$ separation applications.

\section{Other one-pot routes}

As for graphene oxide (GO), Hummer's-like routes have been specifically designed to synthesize oxidized BNNSs [73-76] by using, for example, a mixture of $\mathrm{H}_{3} \mathrm{PO}_{4}$ and $\mathrm{H}_{2} \mathrm{SO}_{4}$ acids [73]. The solution has been later treated at $70{ }^{\circ} \mathrm{C}$ for $12 \mathrm{~h}$, before adding $\mathrm{H}_{2} \mathrm{O}_{2}$ to stop the oxidation process. HO-BNNSs can be also obtained in a solution of $\mathrm{H}_{2} \mathrm{SO}_{4}$ and $\mathrm{KMnO}_{4}$ at the mild temperature of $40^{\circ} \mathrm{C}$ for $6 \mathrm{~h}$ followed by a treatment with $\mathrm{H}_{2} \mathrm{O}_{2}$ at $110{ }^{\circ} \mathrm{C}$ for $48 \mathrm{~h}$ [75].

HO-BNNS with large lateral size, around $2 \mu \mathrm{m}$, and a thickness of 4-14 $\mathrm{nm}$ has been produced by a three-step exfoliation strategy, involving a series of pretreatment-intercalation-exfoliation processes [77]. 


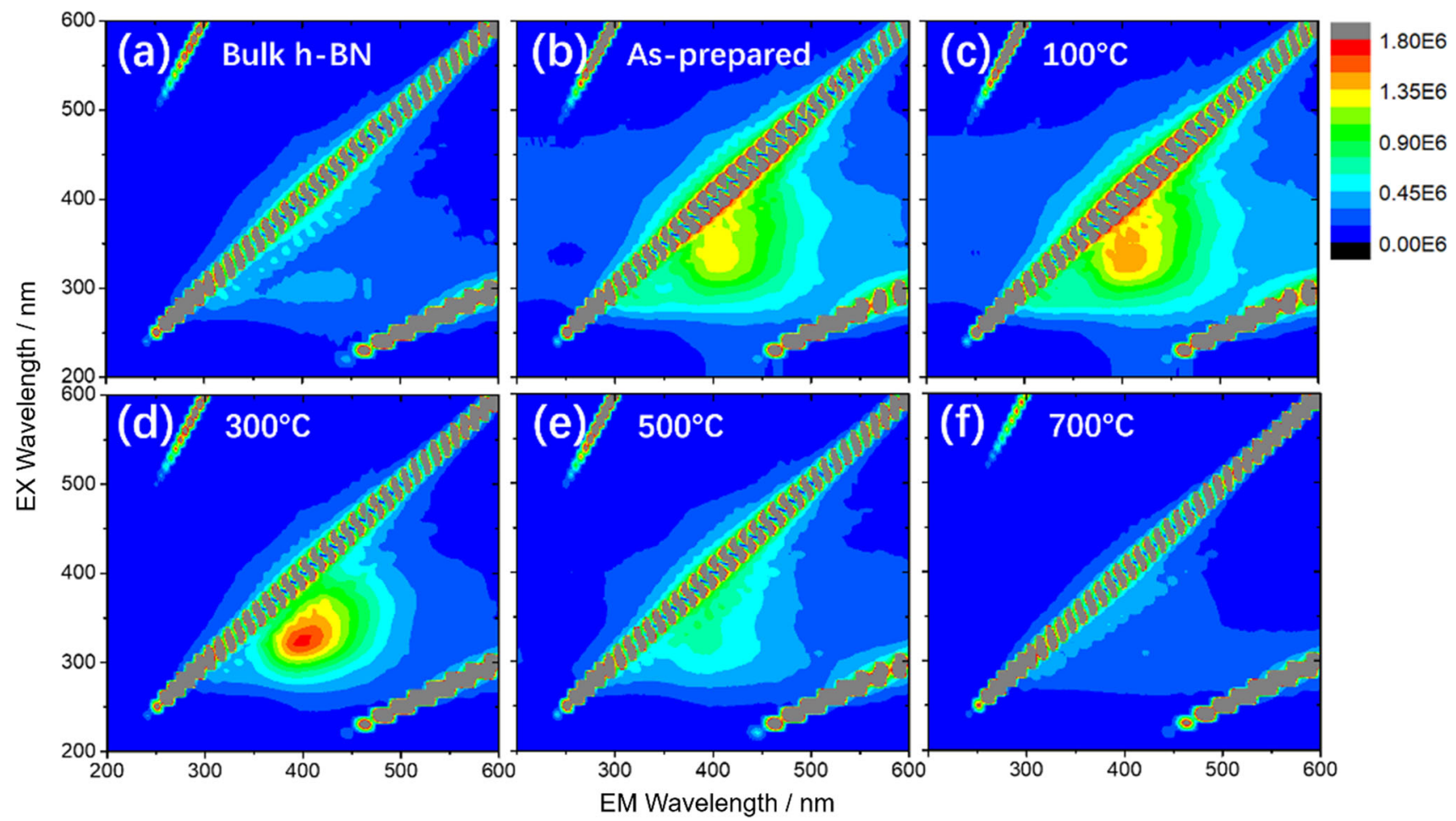

Figure 7 3D PL excitation-emission-intensity spectra of HO-BNNSs after treatment in air with an increasing temperature. Reproduced from Ref. [58] with permission of Copyright (2020) IOP Publishing.

Figure 8 A scheme on BNNSs prepared via ballmilling systems with synergetic effect of mechanical force and chemical peeling.

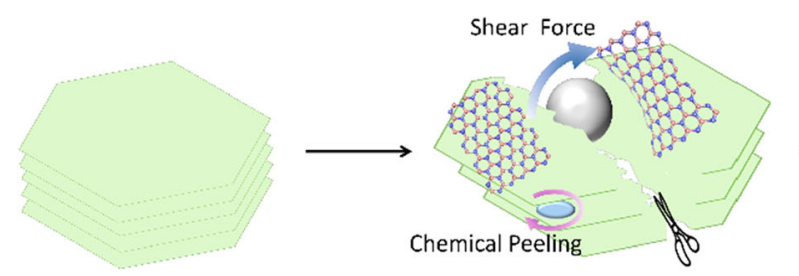

Raw BNs

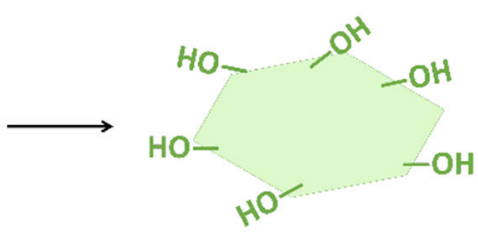

HO-BNNSS
In short, pretreatment of $h$-BNs has been performed by using a mixture of $\mathrm{H}_{2} \mathrm{SO}_{4}$ and $\mathrm{HNO}_{3}$ and intercalation has been carried out by stirring in $\mathrm{NaOH}$ solution. At last, exfoliation has been obtained via microwave-assisted processing in the presence of $\mathrm{NH}_{4} \mathrm{HCO}_{3}$.

Ions-intercalation of $\mathrm{Na}^{+}$and $\mathrm{OH}^{-}$can improve the exfoliation yield of $h$-BN (Fig. 9a) [78]. Interestingly, the obtained HO-BNNSs exhibit nonlinear optical (NLO) response with a positive nonlinear absorption coefficient under excitation at 532 and $1064 \mathrm{~nm}$, suggesting a potential application in optical limiting (OL) (Fig. 9b, c). Intercalation-exfoliation can also be realized using $\mathrm{LiCl}$ by means of a hydrothermal treatment [79].
The presence of edge-hydroxylated groups in $\mathrm{HO}-$ BNNSs prepared at $850{ }^{\circ} \mathrm{C}$ has been detected via an electron energy loss spectroscopy (EELS) [80]. Due to the large amount of $\mathrm{OH}$ groups, the addition of only $0.07 \%$ of HO-BNNS in poly(N-isopropylalacrylamide) (PNIPAM) contributes to improvement in thermal conductivity of $41 \%$.

Strong shear exfoliation forces can be developed using high-speed dispersion homogenizers [81]. This method allows for an efficient production of $\mathrm{HO}-$ BNNSs in water without using high temperature, strongly acidic or alkaline environments. BN precursor in water is shear-exfoliated at room temperature with the support of sodium dodecyl sulfate (SDS). The hydroxylated BNNSs can be easily filtered to remove the SDS by centrifugation. 
(a)

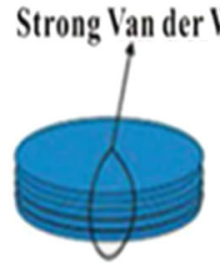

(b)

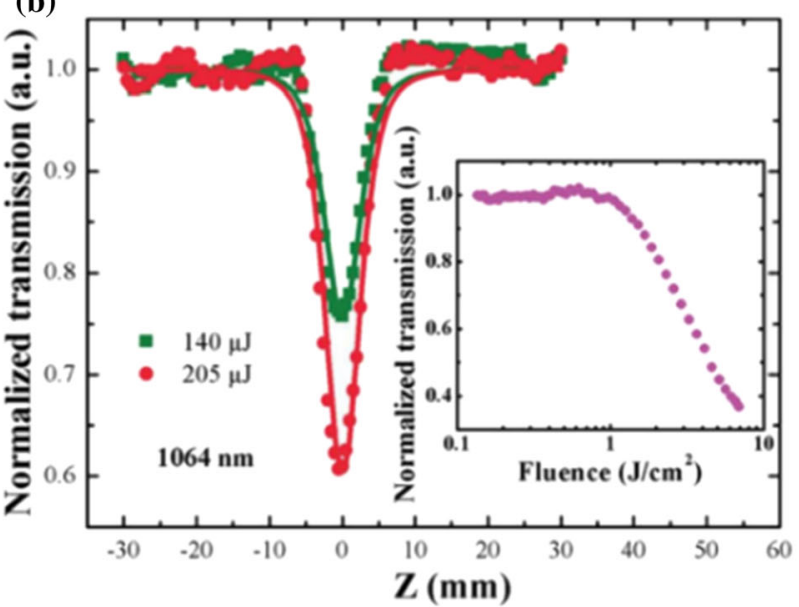

aals force

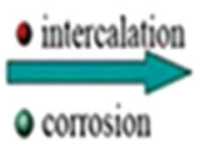

ions intercalation

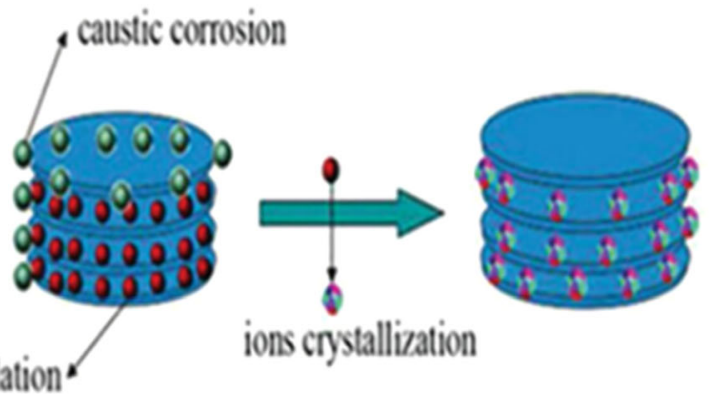

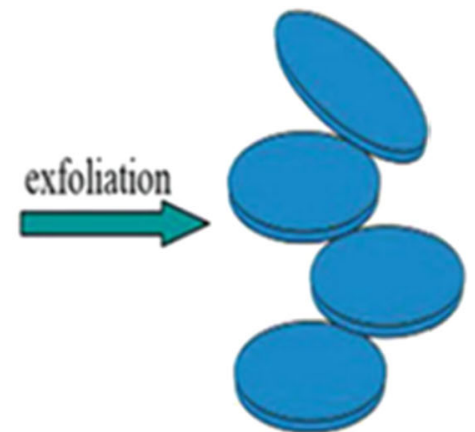

(c)

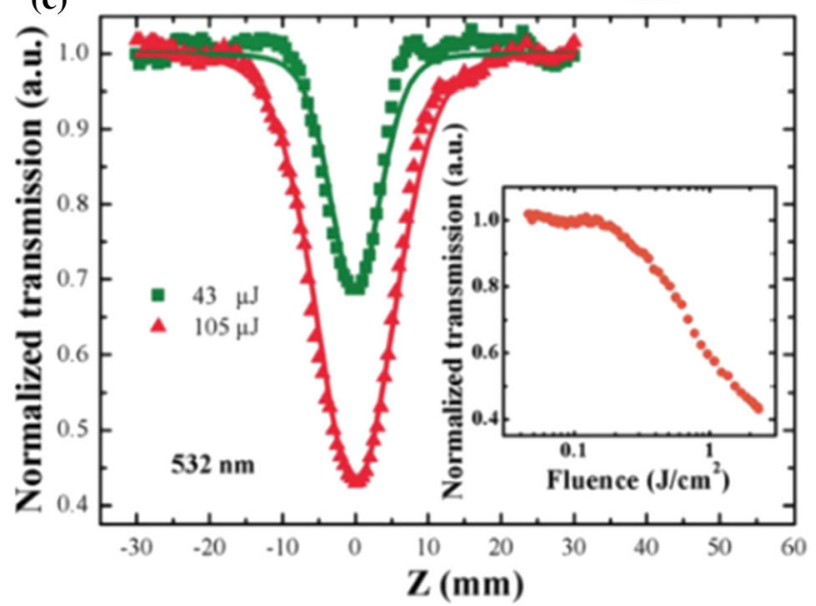

Figure 9 a A scheme on exfoliation of $h$-BNs into HO-BNNSs by ions-intercalation. $\mathbf{b}, \mathbf{c}$ Z-Scan results of HO-BNNSs aqueous solutions under excitation of b 532 and c $1064 \mathrm{~nm}$. Reproduced from Ref. [78] with permission of Copyright (2016) John Wiley and Sons.

(a)

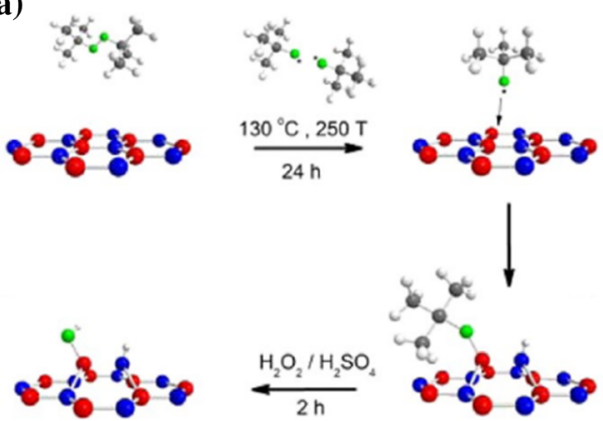

Figure 10 a Schematic preparation of HO-BNNSs from TBPfunctionalization to hydroxyl-functionalization. $\mathbf{b} \mathrm{UV}-\mathrm{Vis}$ spectra of bare BNNSs and HO-BNNSs in aqueous solution, the inset

\section{Two-pots: from BN to BNNS then HO-BNNS}

$h$-BNNSs are usually prepared by the sonication of their bulk counterpart. The layers can be further hydroxylate by carrying out a series of post-treatments under acid, alkali, oxidant, etc.[82-88].

Figure 10a shows a strategy to functionalize $h$ BNNSs via two synthesis steps [82]. A peroxide reagent, di-tert-butylperoxide (TBP), is firstly

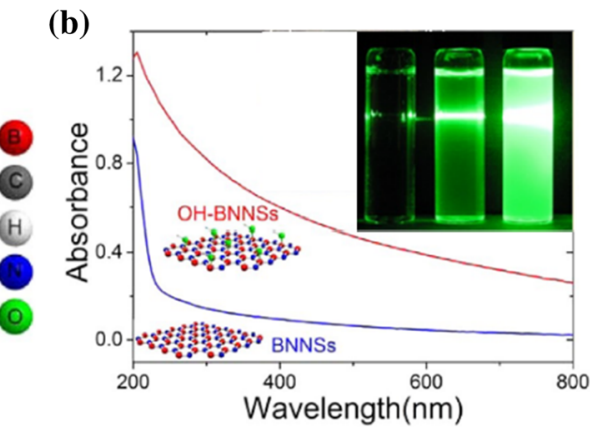

shows pictures of pure water, BNNSs and $\mathrm{OH}-\mathrm{BNNSs}$ in water (from left to right). Reproduced from Ref. [82] with permission of Copyright (2012) American Chemical Society.

introduced to covalently graft alkoxy groups on $\mathrm{B}$ atoms of BNNS, and then, the treatment of $\mathrm{H}_{2} \mathrm{SO}_{4}$ / $\mathrm{H}_{2} \mathrm{O}_{2}$ hydrolytically converts alkoxy into hydroxyl groups. The functionalization by $\mathrm{OH}$ groups increases the solubility of BNNSs in water reaching a remarkable value of $\sim 0.1 \mathrm{mg} \mathrm{mL}^{-1}$ (Fig. 10b). The addition of HO-BNNSs (0.1 wt\%) into PVA increases the strain-to-break value up to $358 \%$, improving the performance of the pristine polymer $(199 \%)$ and the 
PVA with BNNSs (223\%). It can be concluded that an efficient dispersion of hydroxylated BNNSs into a polymeric matrix is able to produce an enhancement of the mechanical properties.

The cytotoxicity on KB cells of HO-BNNSs, obtained by $h$-BN sonication and hydroxylation under treatment in $\mathrm{H}_{2} \mathrm{O}_{2}$ and $\mathrm{H}_{2} \mathrm{SO}_{4}$, has been tested using an MTT colorimetric assay [84]. The results show a good compatibility with more than $90 \%$ of living cells at the concentration of $500 \mu \mathrm{g} \mathrm{mL}^{-1}$ suggesting a potential application for bioimaging.

Hydroxylation has been also achieved in hydrothermally treated $h$-BNNS in $\mathrm{NaOH}$ solution [86]. A 3D hybrid aerogel of epoxy/graphene nanosheet/HO-BNNS has been prepared in a second step. After a 20-cycles compression measurement, the hybrid aerogel preserves $97 \%$ of the original height, demonstrating good compressibility and superelasticity.

HO-BNNSs obtained by oxidation of BNNSs in $\mathrm{HNO}_{3}$ can enhance the dispersion of BNNSs and empower their interfacial interaction with poly(vinylidene fluoride) (PVDF), resulting in an improvement of the corresponding composite dielectric constant and breakdown strength [87]. Consequently, the energy storage density of PVDF/ HO-BNNSs can reach up to $13.1 \mathrm{~J} \mathrm{~cm}^{-3}$, a great enhancement compared with pristine PVDF $(440 \%$, $3.0 \mathrm{~J} \mathrm{~cm}^{-3}$ ) and PVDF/BNNSs (166\%, $\left.7.9 \mathrm{~J} \mathrm{~cm}^{-3}\right)$.

\section{Two-pots: from BN to HO-BN then HO-BNNS}

Hydroxylated $h$-BNNSs can also be obtained by exfoliating bulk HO-BNs [89-92]. According to $\mathrm{Fu}$ et al. [89], HO-BNNSs can be prepared by the following two steps: firstly, a hydrothermal method is used to hydroxylate $\mathrm{BN}$ powders by $\mathrm{NaOH}$ and $\mathrm{KOH}$; in a second step, the HO-BNs can be exfoliated by sonication. The authors have also assembled the HO-BNNSs into papers showing a thermal conductivity of $58 \mathrm{~W} \mathrm{~m}^{-1} \mathrm{~K}^{-1}$. It is reported that the hydroxylation enables an efficient phonon transfer between adjacent sheets and produces a significant decrease in the interfacial thermal resistance.

Phosphorylated BNNSs obtained by proceeding a reaction between $-\mathrm{OH}$ groups of $h$-BNNSs and $\mathrm{H}_{3} \mathrm{PO}_{4}$ can be coated onto carbon steel Q235 substrate by electrophoretic deposition to increase the corrosion resistance. Thus, a passivation film formed by BNNSs can be applied for metal protection [90].
A simple and efficient method to simultaneously exfoliate and functionalize $h$-BNs is ball milling in the presence of sucrose. This method produces a high product yield of $87 \%$ [91] (Fig. 11). HO-BNNSs have been obtained by hydrolysis of the sucrose-grafted BNNSs. Sucrose/BNNSs can be well dispersed in both water and organic liquids. The BNNS/PVA composite films show an enhancement in tensile strength and thermal dissipation capability compared to PVA films.

\section{Bottom-up routes for hydroxylated BNNSs}

Bottom-up techniques allow an effective control of $h$ BN systems growth. So far, several bottom-up techniques have been developed to prepare hydroxylated BNNSs, i.e., chemical vapor deposition (CVD) [93], high-pressure [94], and high-temperature [95-98] methods.

BNNSs has been grown on a copper foil from borazine by CVD. BNNS coating exhibits multiple advantages and, among the others, it provides a good oxidation and corrosion protection of the foil [93].

Precursors such as boric acid and ammonia $\left(\mathrm{H}_{3} \mathrm{BO}_{3}\right.$ and $\mathrm{NH}_{3}$ ) are frequently employed in high yield synthesis. For example, Singh et al. [94] synthesized HO-BNNSs with $\mathrm{H}_{3} \mathrm{BO}_{3}$ and $\mathrm{NH}_{3}$ as precursors by high-pressure route $\left(700{ }^{\circ} \mathrm{C}, 10 \mathrm{GPa}, 24 \mathrm{~h}\right)$. The resulting non-toxic materials make HO-BNNSs potential candidates for boron neutron capture therapy.

HO-BNNSs are also produced by a combination of $\mathrm{H}_{3} \mathrm{BO}_{3}$ and urea thermal treatment $\left(950{ }^{\circ} \mathrm{C}\right)$ in $\mathrm{N}_{2}$ atmosphere and sonication of the bulk BN [95]. The product shows a high fluorescent quenching ability and different affinity toward single-stranded and double-stranded DNA, allowing a sensing platform for complementary DNA fragments.

One of the most efficient preparations is a gramscale synthesis which reaches $88 \%$ of BNNSs yield [97]. The method has been developed as a multi-step process: (i) magnesium borate has been firstly synthesized through a solid-phase process by calcination of $\mathrm{H}_{3} \mathrm{BO}_{3}$ and $\mathrm{Mg}(\mathrm{OH})_{2}$; (ii) magnesium borates has been then heated in a $200 \mathrm{sccm} \mathrm{NH} \mathrm{NH}_{3}$ atmosphere to form $\mathrm{MgO}-\mathrm{BN}$ with core-shell structure; (iii) $\mathrm{HO}$ BNNSs have been finally obtained by ultrasonic cleaning in $\mathrm{HCl}$ solution to remove the magnesium oxide (Fig. 12). Coupling the experimental results with theoretical simulations with DFT analysis, the 
Figure 11 A proposed chemical reaction mechanism for the preparation of sucrosegrafted HO-BNNSs by mechanochemical exfoliation. Reproduced from Ref. [91] with permission of Copyright (2019) John Wiley and Sons.

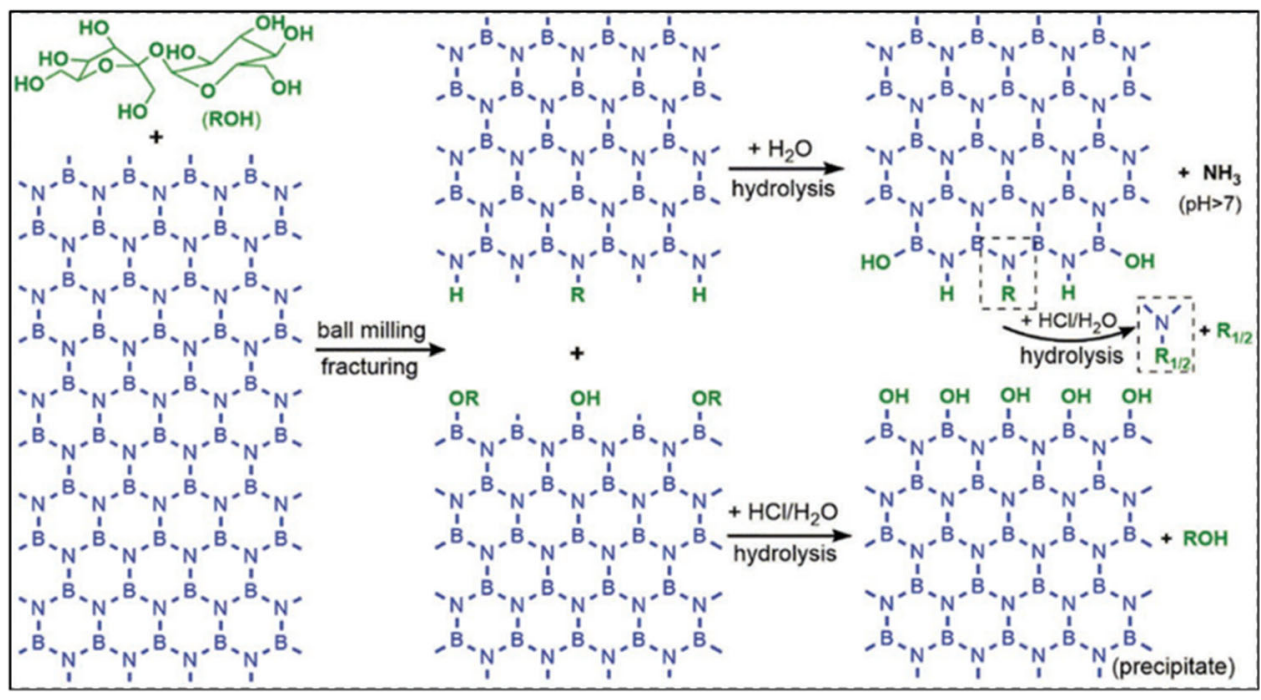

Figure 12 An illustration of HO-BNNS prepared via a borate nitridation method. Reproduced from Ref. [97] with permission of Copyright (2018) American Chemical Society.

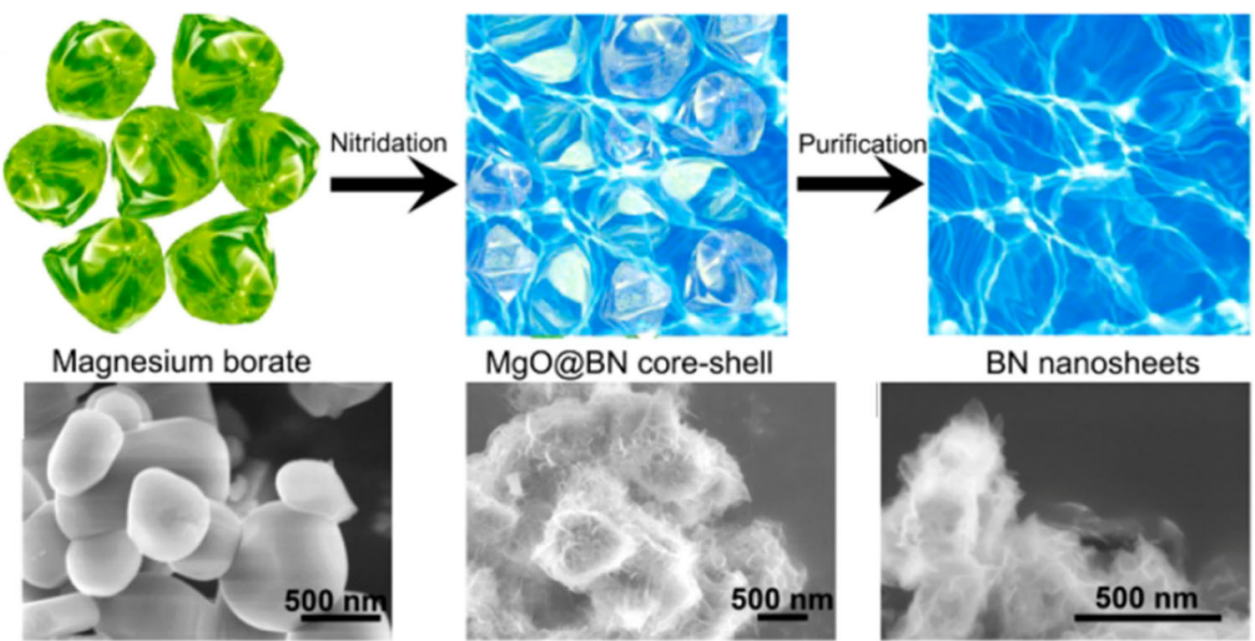

authors have proposed a vapor-solid-solid mechanism where the reaction between vapor $\mathrm{NH}_{3}$ and solid borates results in the production of BNNSs at the vapor-solid interfaces.

\section{Theoretical models for hydroxylated BNNSs}

The functionalization of $h-\mathrm{BN}$ is still at its early stage. Because of the reactivity of boron compounds, theoretical calculations are essential to gain an in-depth insight into the electronic and mechanical properties of layered BN [2]. Density functional theory (DFT) and molecular dynamics (MD) simulations provide valuable predictions and corroborations on the impact of hydroxyl chemical species on the BNNSs surfaces [99-104].

Wang et al. [99] investigated the hydroxyl functionalization of $h$-BNNSs by generalized gradient approximation (GGA) with double numerical basis sets plus polarization function (DNP), taking a $(5 \times 5)$ supercell with $x-y$ plane periodic conditions as a model. In this work, different $\mathrm{OH}$ radical coverage percentages have been considered and the corresponding electronic properties and structural stability have been evaluated. The simulations have identified the boron atom as the most favorable site for $\mathrm{OH}$ adsorption. The $\mathrm{OH}$ adsorbed at the boron site produces a deformation of $h$-BN sheet. Correspondingly, the involved boron is moved out of the sheet plane by $1.25 \AA$, increasing the $\mathrm{B}-\mathrm{N}$ bond length up to $1.53-1.54 \AA$ (pristine bond is $1.45 \AA$ ). In this case, the $\mathrm{B}$ hybridization changes from $\mathrm{sp}^{2}$ to $\mathrm{sp}^{3}$. As shown in Fig. 13a, a covalent B-O bond can form between $-\mathrm{OH}$ and $\mathrm{B}$ site of $h$-BN surface with a length of $1.51 \AA$, which can elongate to $2.40 \AA$ in the 
Figure 13 DFT study about $h$ $\mathrm{BN}$ monolayer functionalized by hydroxyl $(\mathrm{OH})$ radicals: a the distance between $\mathrm{OH}$ radical and $h$-BN sheet; b optimized stable configuration and the respective adsorption energies of $20 \%, 60 \%$, and $100 \% \mathrm{OH}$ coverage on $h$-BN sheet; c optimized stable configuration and respective adsorption energies of $8 \% \mathrm{OH}$ coverage on $h$-BN sheet. Reproduced from Ref. [99] with permission of Copyright (2013) Springer.

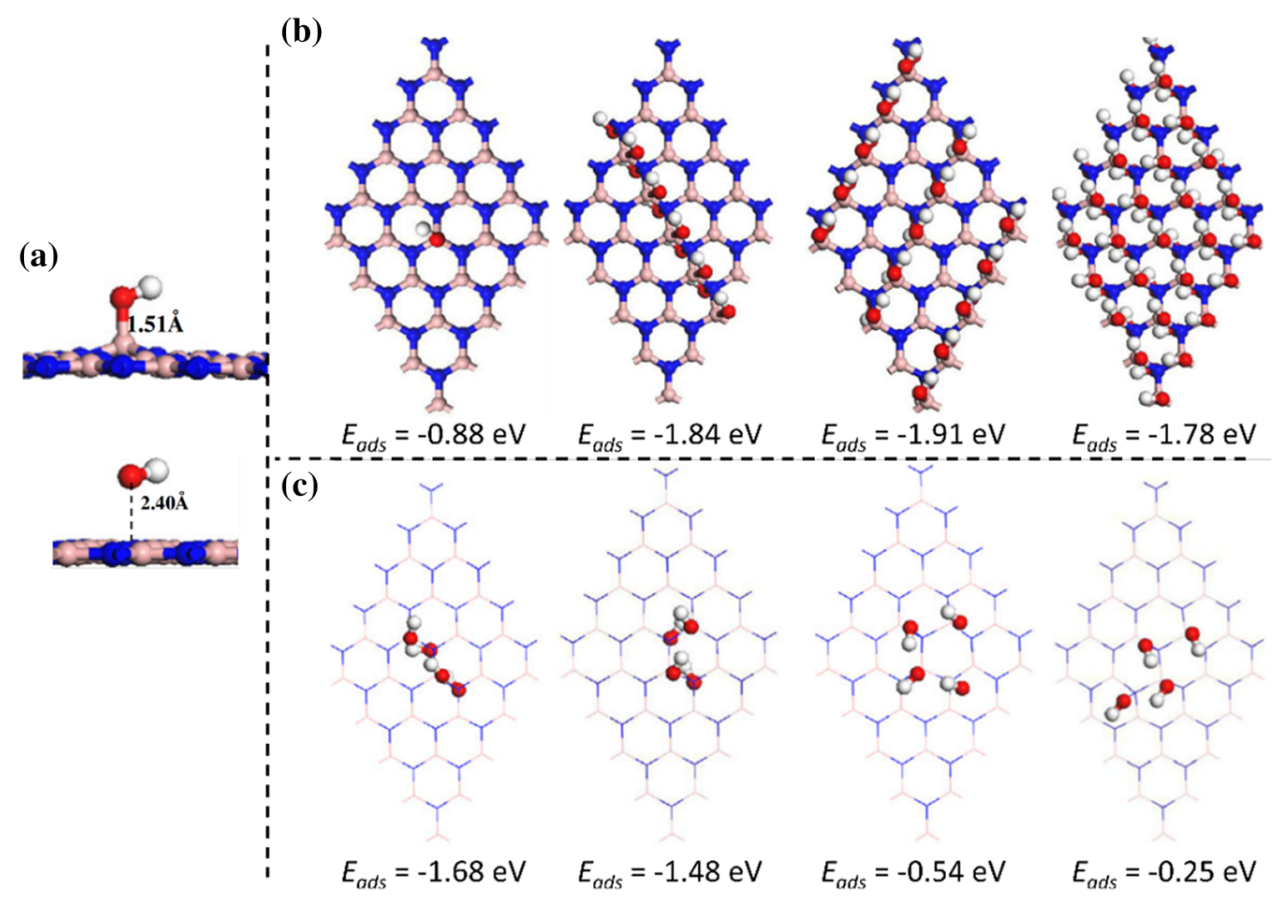

diffusion transition state. Figure $13 \mathrm{~b}$ shows that the amount of hydroxyl groups on $h$-BNNSs will influence their stability. The most stable configuration of a single $\mathrm{OH}$ radical presents an adsorption energy of $-0.88 \mathrm{eV}$. When increasing $-\mathrm{OH}$, the adsorption energy per radical changes from $-1.84 \mathrm{eV}$ for $20 \%$ $\mathrm{OH}$ coverage to -1.91 and $-1.78 \mathrm{eV}$ for 60 , and $100 \%$, respectively. Therefore, $h$-BNNSs functionalized with $60 \%-\mathrm{OH}$ radicals possess the most stable structure. Additionally, $\mathrm{OH}$ groups can be absorbed from the same side or both sides along a zigzag line or armchair configurations. With four $\mathrm{OH}$ radicals (Fig. 13c), the most favorable configuration is a linear adsorption structure along with zigzag chain stitch on both sides of BN.

Grosjean et al. [101] have reached similar conclusions by exploring the chemisorption of $\mathrm{OH}^{-}$ions on the $h$-BN surface via an implicit solvent scheme. The calculation has confirmed that the strongly favorable adsorption of anionic hydroxide on BN layer is connected to the $\mathrm{sp}^{3}$ rehybridization of the bonding atom, boron anchoring site, which results in a negative surface charge of the layered materials. In particular, the authors demonstrate a superior reactivity of $h$-BN surfaces in contact with hydroxyl anions in comparison with graphene, whose reactivity to $\mathrm{OH}$ radical results less marked.

The mechanical as well as the electromechanical properties of $h$-BNNSs, before and after hydroxylation, have also been investigated by DFT [102]. Two different hydroxylation configurations have been tested: ordered and amorphous. The latter is expected to reflect the experimental results better. The increase in $h$-BN surface functionalization promotes a progressive increase in interlayer distance (Fig. 14a). For both configurations, at $60 \%$ coverage ratio, the interlayer distance approaches to a maximum of about $5.8 \AA$, not so far from the measured value of $6.9 \AA$ [102]. In general, Young's modulus decreases under chemisorption of $\mathrm{OH}$ groups. For example, for amorphous coverage, the module decreases from 436 to $284 \mathrm{GPa}$. However, unlike graphene oxide, the hydroxylation of boron nitride has less influence on the mechanical properties, making it a better material in several engineering applications. Moreover, the presence of $-\mathrm{OH}$ can reduce their bandgap and endow $h$-BNNSs with more electro-conductive ability (Fig. 14b). More precisely, it has been reported that under the application of a strain, the bandgap of $h$-BNNSs reduces from $1.7 \mathrm{eV}$ down to $0.8 \mathrm{eV}$ by increasing the hydroxylation ratio from $20 \%$ up to $60 \%$.

Molecular dynamics simulations have been tested to investigate the fracture mechanisms in HO-BNNSs [104]. Coverage of $-\mathrm{OH}$ on $h$-BNNS has a deteriorating effect on the mechanical properties of BNNSs. As for DFT calculations, the fragility of $h$-BN sheets grows with the hydroxylation. Nevertheless, $h$ - 


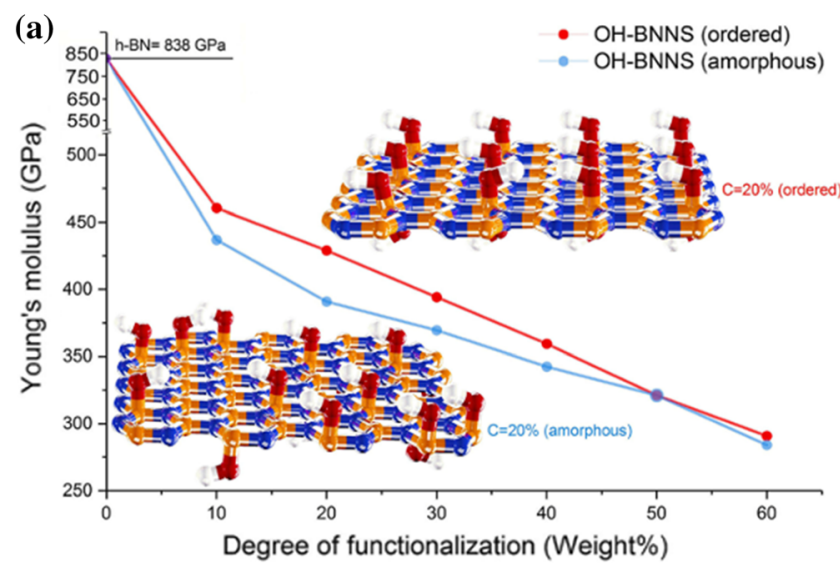

Figure 14 Study of mechanical properties of hydroxylated $h$ BNNs: a Young's module $(\mathrm{GPa})$ as a function of the coverage configurations; b electronic bandgap values for 20 and $60 \%$

BNNSs affected by cracks can be strengthened by suitable $\mathrm{OH}$ functionalization. In particular, crack edge passivation with $\mathrm{OH}$ shows a $32 \%$ improvement of fracture toughness, and BNNSs with edge passivation a $48 \%$ increase on tensile strength.

\section{Hydroxylated BNNTs}

\section{Theoretical studies of hydroxylated BNNTs}

DFT and MD investigations have been carried out to explore the optimized structure and geometry parameters of hydroxylated BNNTs [105-110]. In contrast with their carbon counterparts, BNNTs present a considerable stability under vacuum conditions and are thought to be good candidates for fieldemission devices. Studies on the adsorption of $\mathrm{O}_{2}$ and $\mathrm{H}_{2} \mathrm{O}$ on an open-ended BNNT have demonstrated that the applications of an electric field increase the stability of adsorbates at the tube tip. The adsorbates contribute to change the field emission properties of the BNNTs with a ionization potential slightly lower for N-rich ended NTs than that B-rich ended [105]. Besides, compared with the isolated BNNT of $4.78 \mathrm{eV}$ energy gap, $\mathrm{OH}$ functional groups on BNNTs only cause a small reduction of $0.31 \mathrm{eV}$, while functionalizing with $\mathrm{SH}$ groups promotes a semiconductormetallic transition. Thus, the semiconductor characteristic is well kept in HO-BNNT systems and, at the same time, the solvation and dispersion properties turn out to be improved by the increase in polarity [106].

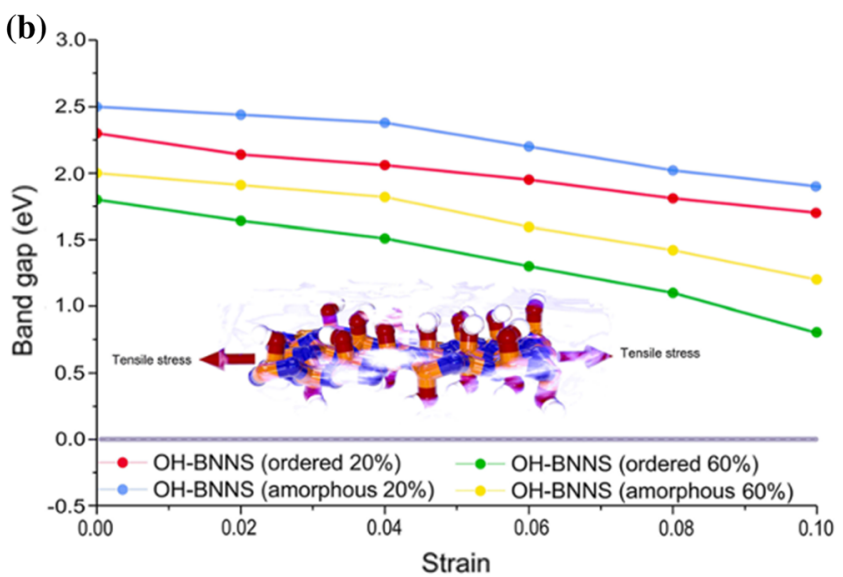

coverage under strain. Reproduced from Ref. [102] with permission of Copyright (2018) AIP Publishing.

Duverger et al. [108] studied the effect of $\mathrm{OH}$ chemisorption on the optimized geometry of BNNTs. The interaction of HO-BNNTs with different molecules, including azomethine and $\mathrm{Pt}(\mathrm{IV})$ complex (anticancer agent), has also been studied. As shown in Fig. 15, the Pt drug molecule located in a symmetric position along the BNNT principal $z$-axis shows the most stable configuration inside the tube, demonstrating the feasibility of BNNTs for future drug therapy. HO-BNNTs as the carrier for another anticancer molecule, the ifosfamide [109], has been also explored. According to the calculations, the encapsulation of ifosfamide can also take place at room temperature, preserving the drug from unwanted interactions before reaching the cell sites.

All these calculations well support the possibility of an effective use of OH-BNNTs for several applications in electronics and nanomedicine and motivate the great experimental effort dedicated to synthesizing BNNTs.

\section{Methods for hydroxylated BNNTs}

Beside in situ hydroxylation in the BNNTs forming process [111, 112], $\mathrm{OH}$ groups can be introduced by a pre-treatment in the presence of $\mathrm{H}_{2} \mathrm{O}_{2}$ [33, 113-116], $\mathrm{HNO}_{3}$ [117], NaOH [118], and other reactants [119, 120] (see Fig. 16). Soares et al. [111] prepared BNNTs with $\mathrm{OH}$ groups by a bottom-up process with $\mathrm{NH}_{4} \mathrm{NO}_{3}$, amorphous boron, hematite (size $<50 \mathrm{~nm}$ ) as precursors. Then, BNNTs were functionalized by glycol chitosan. Due to the non-covalent coating of glycol chitosan, the products could be further 
Figure 15 a Lateral and

$\mathbf{b}$ perpendicular view of optimized geometry of singlewalled HO-BNNTs. c Lateral view of the amino derivative azomethine Pt drug-BNNT.

d Relationship between adsorption energy and the distance " $d$ ". Reproduced from Ref. [108] with permission of Copyright (2014) The Royal Society of Chemistry. (a)

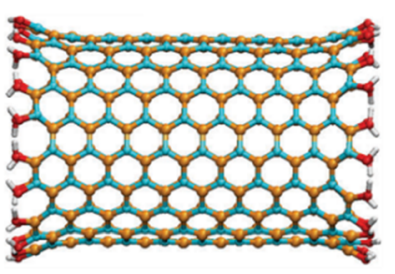

(b)

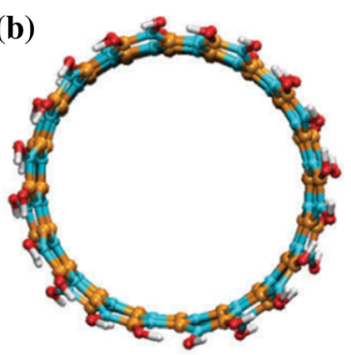

(c)
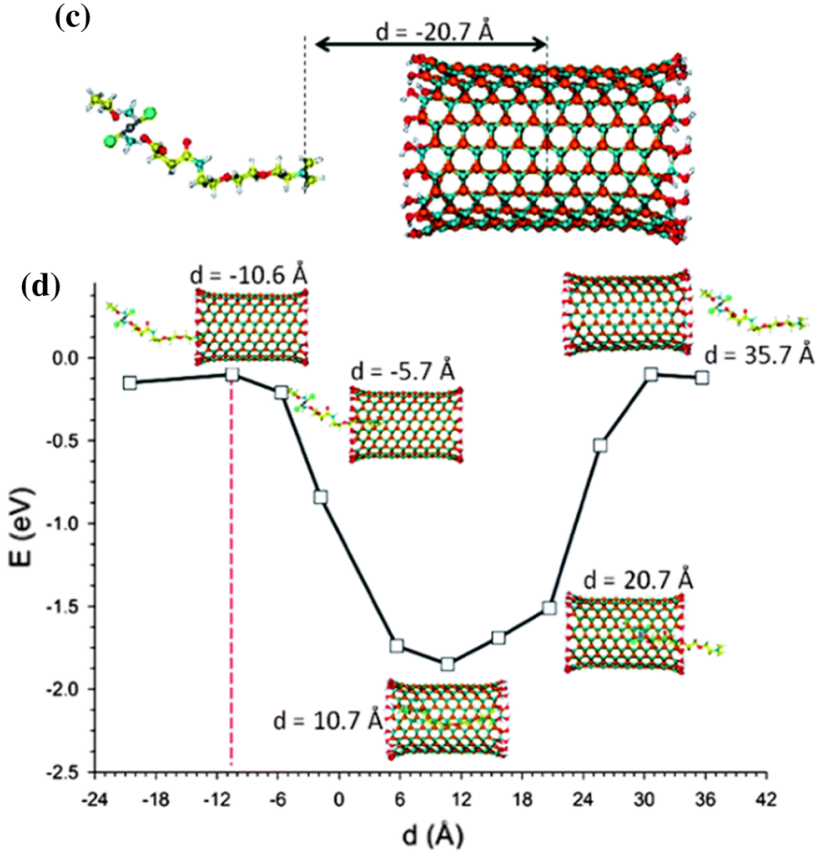

(a)

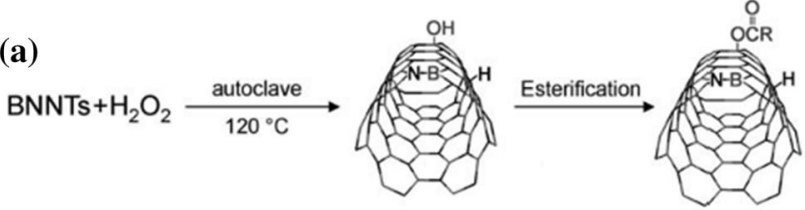

(b)

(c)
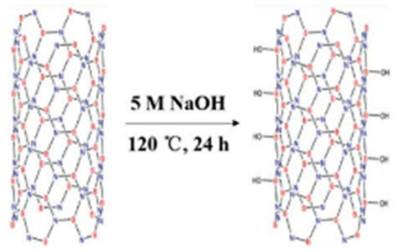

(d)

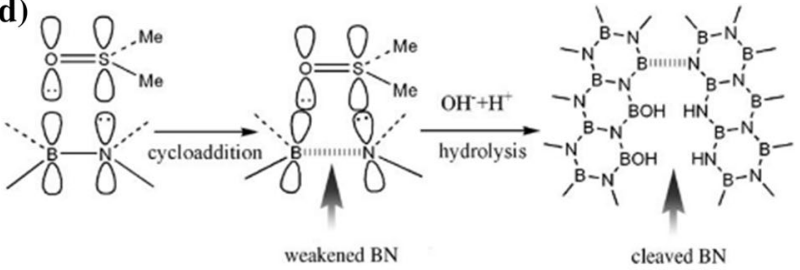

(e)

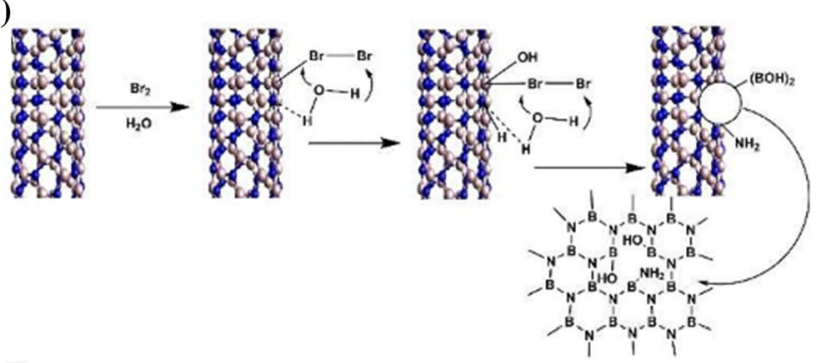

and Sons, Copyright (2012) Elsevier, Copyright (2018) The Royal Society of Chemistry, Copyright (2006) John Wiley and Sons, and Copyright (2018) John Wiley and Sons.

could be further esterified by the chemical reaction of $\mathrm{COOH}$ and $\mathrm{OH}$. The resulting HO-BNNTs appear more effective for mechanical reinforcement of polymers, e.g., polycarbonate (PC) and polyvinyl butyral (PVB), in comparison with the bare BNNTs.

can be achieved via reactions of $\mathrm{BN}$ with $\mathrm{H}_{2} \mathrm{O}_{2}$ through a hydrothermal route [33]. The HO-BNNTs 
HO-BNNTs have also been tested for applications in biotechnology, such as drug delivery [113] and gene silencing [115], after glutaraldehyde modification.

Functionalizing BNNTs with $\mathrm{OH}$ groups represents a successful strategy for silanization [117]. OHactivated BNNTs under the strong oxidation of $\mathrm{HNO}_{3}$ (Fig. 16b) can strongly react with APTES by sonication. APTES-grafting on BNNTs allows covalent functionalization with different biological molecules, with encouraging possible developments in biotechnology. Moreover, it has been demonstrated that the hydrolyzation of BNNTs is a necessary step for a correct dispersion in specific polymers [118]. $\mathrm{OH}-\mathrm{BNNT}$ s obtained in refluxing $\mathrm{NaOH}$ have been grafted by aminopropyltrimethoxy (APS) (see Fig. 16c). The APS-functionalization improves the BNNTs dispersion in epoxy resin, leading to $650 \%$ enhancement in thermal conductivity and $20 \%$ reduction in the thermal expansion coefficient.

Some unconventional approaches have also been proposed to realize the hydroxylation of BNNTs. A solvothermal treatment of BNNTs in DMSO can peel B-N bonds and introduce $\mathrm{OH}$ on B sites (Fig. 16d) [119]. Guan et al. [120] designed a liquid bromine treatment to yield both hydroxyl- and amino-functionalized BNNTs (see Fig. 16e). $\mathrm{OH}$ and $\mathrm{NH}_{2}$ groups provide BNNTs with $\mathrm{pH}$-switchable solubility in water. In fact, the bi-functionalized BNNTs are stable in an aqueous solution with $\mathrm{pH}$ in the range of $4-8$, but precipitate when $\mathrm{pH}$ is out of range.

\section{Other hydroxylated $\mathrm{BN}$ materials}

Apart from BNNSs and BNNTs, there are some other hydroxylated $\mathrm{BN}$-based materials that are progressively attracting the attention, such as porous BNs, nanospheres, nanoparticles, nanowires, hollow shells, and nanoscrolls.

\section{Hydroxylated porous $\mathrm{BN}$ materials}

Porous $h$-BN materials offer the opportunity to modulate the properties and expand the fields of application. A high-temperature treatment of $\mathrm{H}_{3} \mathrm{BO}_{3}$ to substitute boron atoms with carbon in $g-\mathrm{C}_{3} \mathrm{~N}_{4}$ [121] is a feasible method to prepare porous HO-BNs (Fig. 17a). Due to $\sim 30$ at $\%$ hydroxylation degree, the aqueous solutions result stable at high HO-BNs concentration $\left(2 \mathrm{mg} \mathrm{mL}^{-1}\right)$ and represent good systems for potential applications in anticancer drug loading and delivery. A non-template strategy to fabricate a $3 \mathrm{D} h$-BN foam-like porous monolith has been developed; it provides samples with a high surface area, up to $1406 \mathrm{~m}^{2} \mathrm{~g}^{-1}$ (Fig. 17b) [122]. It has also been developed a template-free synthesis to obtain porous $\mathrm{HO}-\mathrm{BNNSs}$ from $\mathrm{B}_{2} \mathrm{O}_{3}$ and ethylene diamine for water cleaning [123].

Under hydroxyl functionalization of exposed (002) plane, porous BNNSs display an enhancement of visible optical absorption [124]. BNNSs incorporation into $\mathrm{TiO}_{2}$ promotes a strong visible-light photocatalytic oxidation of organics in solution due to the synergic effect of $h$-BNs visible absorption and charge transfer to $\mathrm{TiO}_{2}$ [124]. In addition, it was found that the electrical resistivity of porous HO-BNs is lower and the photocurrent is higher in comparison with commercial $h$-BNs, extending the application field to photocatalysis and photovoltaic engineering [125].

\section{Hydroxylated BN nanospheres}

Compared with other nanostructures, $h$-BN nanospheres possess several advantages in pollution cleaning and drug delivery, especially when they have a hollow structure. Liu et al. [126] prepared $h$ BN spheres with nanosheet-structure (see Fig. 18a) by thermally evaporating boron powders in $\mathrm{NH}_{3}$ atmosphere under catalyzation of $\mathrm{CoFe}_{2} \mathrm{O}_{4}$ and $\mathrm{CoO}$. The corresponding adsorption capacities for dyes, tested with malachite green and methylene blue, were up to 324 and $233 \mathrm{mg} \mathrm{g}^{-1}(\mathrm{wt}($ dye $) / \mathrm{wt}$ (material)). The adsorption of $\mathrm{Cu}^{2+}, \mathrm{Pb}^{2+}$, and $\mathrm{Cd}^{2+}$ heavy metal ions could reach $678.7,536.7$, and $107.0 \mathrm{mg} \mathrm{g}^{-1}$, respectively, which are much higher than other reported materials (e.g., activated BN and carbon, soy protein hollow microspheres) [126].

As shown in Fig. 18b, another 3D $h$-BN sphere with nanosheet-structure has been obtained by growing BNNSs in a crystalline metal-organic framework (MOF) [127]. In this work, a novel MOF-sphere containing boron was firstly designed and function as template. In the first step, the zeolitic nanoparticles react with boric acid by a solvothermal treatment and form a new spherical boron-containing MOF. The subsequent annealing at $1000{ }^{\circ} \mathrm{C}$ in ammonia environment produces $h$-BN spheres. Beside the intriguing morphological characteristics, the obtained material has shown interesting properties in both catalysis and energy storage. 

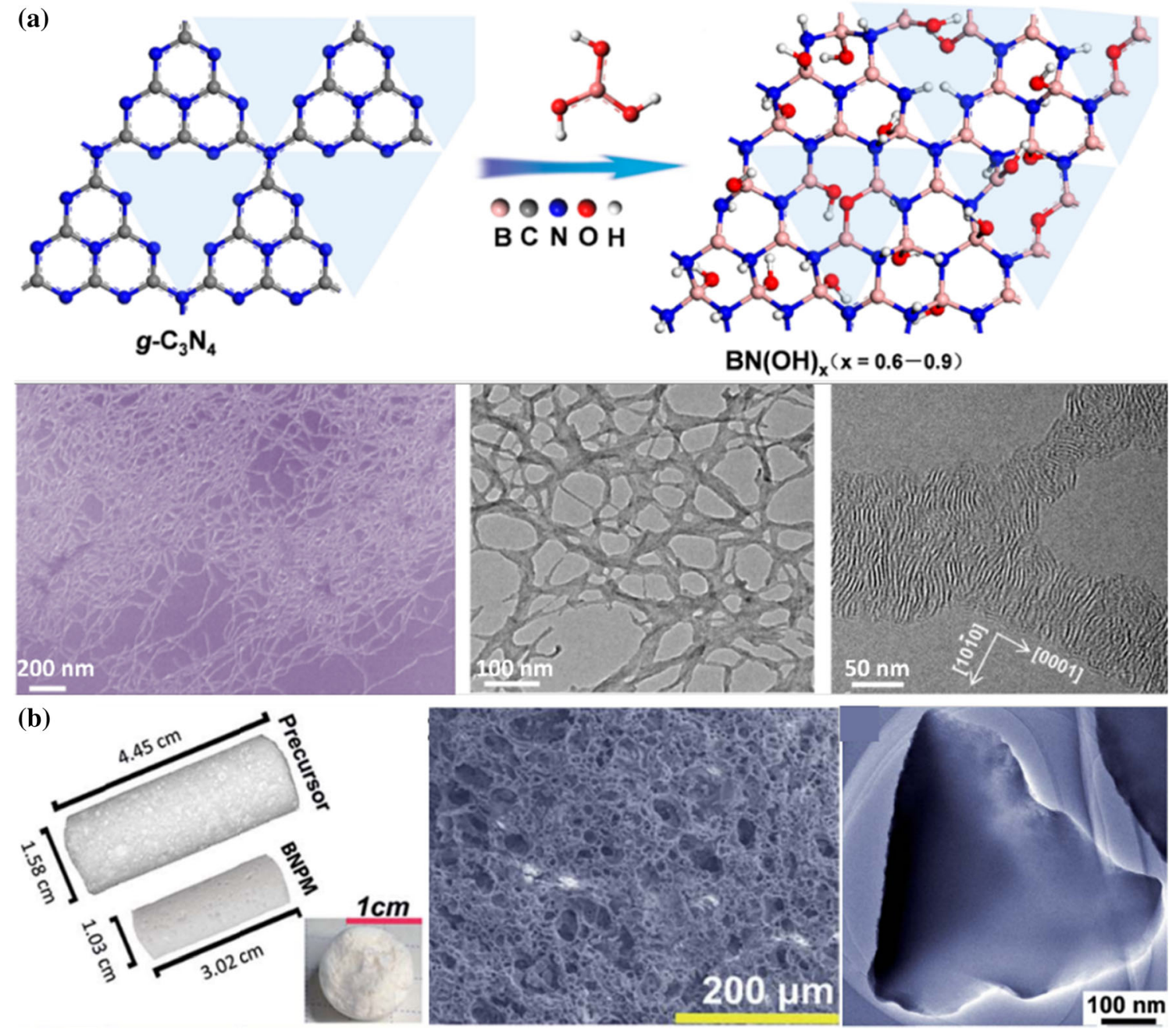

Figure 17 a Scheme of the thermal substitution reaction between $g-\mathrm{C}_{3} \mathrm{~N}_{4}$ and $\mathrm{H}_{3} \mathrm{BO}_{3}$ to prepare porous $\mathrm{HO}-\mathrm{BNs}$, and the relevant SEM and TEM images. b Picture of $3 \mathrm{D} h$-BN foam-like porous monolith, and the relevant SEM and TEM image. Reproduced

A sol-gel route has also been developed to prepare $h$-BN nanospheres from $\mathrm{H}_{3} \mathrm{BO}_{3}$ and melamine [128]. In brief, a carbon spheres template has been impregnated by $\mathrm{H}_{3} \mathrm{BO}_{3}$. melamine gel, and then $h$-BN spheres have been formed through a thermal process (500 and $1000{ }^{\circ} \mathrm{C}$, in $\mathrm{N}_{2}$ flow). The nanospheres present a high negative charge, which has been attributed to the adsorption of $\mathrm{OH}$ groups. This results in an excellent long-term dispersion stability in water without the need of further surface modification.

$h$-BN nanospheres have been loaded for delivering anticancer drugs $[129,130]$. The $h$-BN spheres can be hydroxylated by $\mathrm{HNO}_{3}$ and modified by APTES and poly(allylamine hydrochlorid)-citraconic anhydride (Fig. 19). The functionalized $h$-BN system can deliver from Refs. [121, 122] with permissions of Copyright (2014) American Chemical Society, and Copyright (2016) The Royal Society of Chemistry.

drugs, such as doxorubicin hydrochloride (DOX), to be released into cancer cells for therapy [130]. It has also been observed that hollow $h$-BN nanospheres are effective systems against tumor growth and may work for cancer treatment [131]. In this report, the authors find that controlled boron release from hollow $h$-BN spheres can inhibit the growth of both androgen-sensitive (LNCap) and androgen-independent (DU145) prostate cancer cells. The preventive properties, along with the high hydrophilicity, make hollow $h$-BN spheres a potential candidate for future anticancer treatments. 


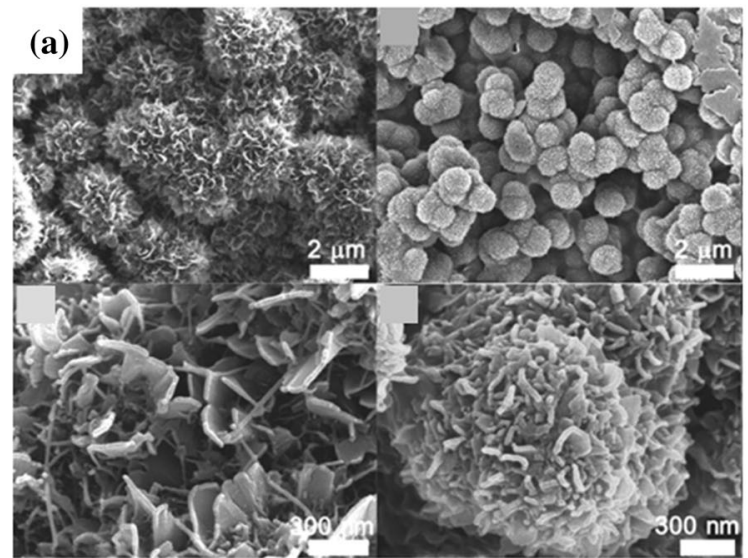

Figure 18 a SEM images of $h$-BN spheres with nanosheetstructure. b Schematic illustration for the preparation of 3D nanosheet-structured $h$-BN sphere. Reproduced from Refs.

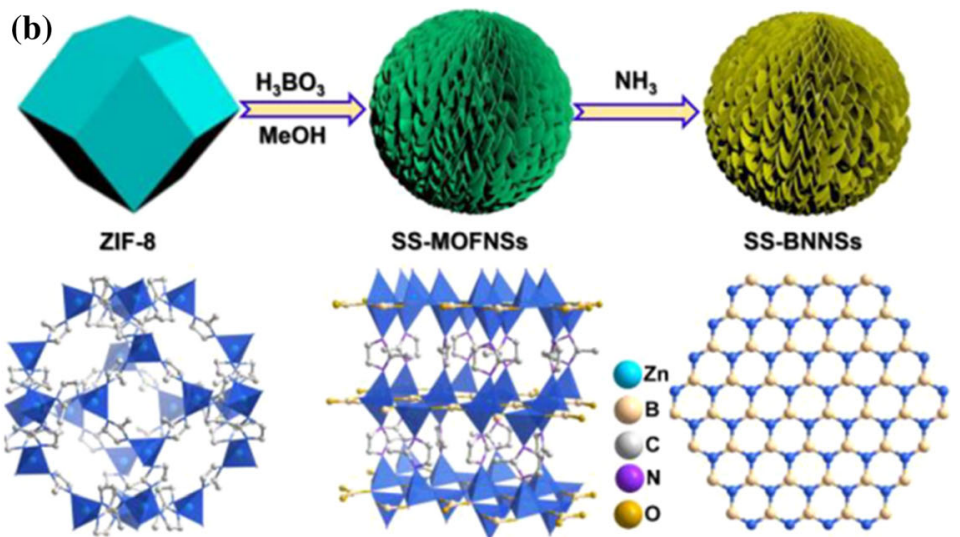

[126, 127] with permissions of Copyright (2015 and 2020, respectively) American Chemical Society.

Figure 19 Schematic illustration of $h$-BN nanospheres after modification for drugs releasing. Reproduced from Ref. [130] with permission of Copyright (2018) Dove Medical Press.

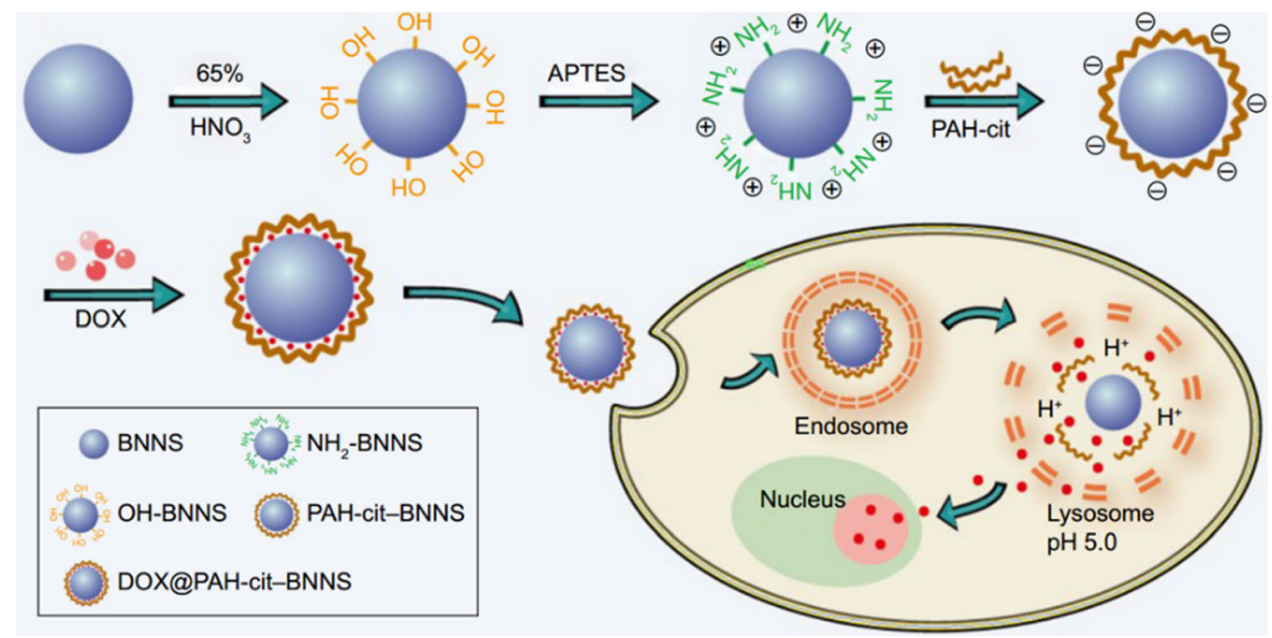

\section{Hydroxylated BN nanoparticles, nanowires and hollow shells}

h-BN nanoparticles can also be produced via CVD using $\mathrm{B}(\mathrm{OMe})_{3}$ as a precursor in $\mathrm{NH}_{3}$ atmosphere. The CVD temperature is a critical parameter for the morphologies of the products [132]; the $h$-BN nanoparticles aggregate and have an irregular shape if the CVD working temperature is lower than $900{ }^{\circ} \mathrm{C}$, while they result well-dispersed and isotropic if the temperatures are higher. Additionally, the intensity of $\mathrm{OH}$ groups at $h$-BN surfaces, studied by monitoring the infrared band $\mathrm{OH}$ stretching vibration at $\sim 3600 \mathrm{~cm}^{-1}$, increases with the rise of temperature. Although the authors enlightened the role of oxygen defects in the morphology of $h$-BN nanoparticles, the mechanism related to the enhanced humidity sensitivity of $h$-BN is not fully comprehended even though the crystalline state prevails on the amorphous state.

Mesoporous $h$-BN nanowires can be synthesized from $\mathrm{H}_{3} \mathrm{BO}_{3}$ and melamine using Pluronic P123 as templating agent for porosity [133]. A thermal treatment at $1000{ }^{\circ} \mathrm{C}$ for $3 \mathrm{~h}$ in $\mathrm{N}_{2}$ atmosphere has been employed for the synthesis. The nanowires porosity and oxygen-doping (B-O, B-OH) significantly improve the adsorptive desulfurization activity for dibenzothiophene, and adsorption ability for 4,6dimethyldibenzothiophene. 
$h$-BNNSs and their hollow shells can be prepared via a bottom-up route with $\mathrm{B}_{2} \mathrm{O}_{3}$ and melamine as precursors by adding $\mathrm{Mg}$ powders [134]. In particular, $\mathrm{Mg}$ powders reduces $\mathrm{B}_{2} \mathrm{O}_{3}$ to $\mathrm{B}$ element via a combustive reaction with heat release; this thermal energy further causes the decomposition of melamine and provides the condition for the formation of $\mathrm{BN}$ structure.

\section{Summary and outlook}

The recent interest caused by $\mathrm{BN}$ has required the development of new synthesis techniques to produce materials of various shapes and sizes and achieve effective control of surface properties. The current methods for obtaining hydroxylated BN-based materials are summarized in Table 2, coupled with an evaluation on their merits. Hydroxyl functionalization can endow BN-based materials with wideranging interesting properties. The advantages of $\mathrm{HO}-\mathrm{BNs}$ include:

(i) The improvement of solvent-soluble and dispersion in the supporting matrices, as well as biocompatibility, non-toxicity;

(ii) The $\mathrm{OH}$-tailored modification by other molecules, such as APTES, APS, glutaraldehyde, and carboxylic acid compound;

(iii) The empowered abilities in drugs delivery, therapeutics, and pharmaceuticals, as well as adsorption and filtration of pollutants (i.e., dyes, oils, heavy metal ions);

Table 2 Evaluation of different methods to prepare hydroxylated BN materials

\begin{tabular}{|c|c|c|c|}
\hline $\begin{array}{l}\mathrm{BN} \\
\text { materials }\end{array}$ & Methods & Evaluation & Refs \\
\hline \multirow[t]{4}{*}{$\begin{array}{l}\text { BNs in } \\
\text { micron- } \\
\text { scale }\end{array}$} & Heating in air & $\begin{array}{l}\text { It is the simplest and most direct way to oxidize and hydroxylate bulk } h \text {-BNs } \\
\text { The thermal treatment is performed at high temperature (over } 1000{ }^{\circ} \mathrm{C} \text { ) } \\
\text { The hydroxyl degree depends on the temperature and time }\end{array}$ & {$[30,34,35]$} \\
\hline & $\begin{array}{l}\text { Treatment in acidic or } \\
\text { alkaline solution }\end{array}$ & $\begin{array}{l}\text { It is efficient and facile, but needs the assist of sonication, heating }\left(<100{ }^{\circ} \mathrm{C}\right) \text {, } \\
\text { and/or stirring }\end{array}$ & {$[32,36-43]$} \\
\hline & $\begin{array}{l}\text { Treatment with strong } \\
\text { oxidants }\end{array}$ & $\begin{array}{l}\text { The use of strong oxidants (i.e., } \mathrm{H}_{2} \mathrm{O}_{2}, \mathrm{KMnO}_{4} \text { ) requires special attention } \\
\text { Acids, e.g., } \mathrm{H}_{2} \mathrm{SO}_{4}, \mathrm{H}_{3} \mathrm{PO}_{4} \text {, are usually added to enhance the process } \\
\text { Sometimes the strong oxidization process can lead to the presence of a few by- } \\
\text { products of nanosheets }\end{array}$ & {$[44,45]$} \\
\hline & Bottom-up routes & $\begin{array}{l}\text { Hydroxylated } h \text {-BNs can be directly obtained by temperature lower than } \\
1100{ }^{\circ} \mathrm{C} \text {. The treatment can generate some other defects in HO-BNs. If the } \\
\text { temperature reaches } 1500^{\circ} \mathrm{C} \text {, the products have to be hydroxylated by the } \\
\text { above methods }\end{array}$ & {$[47-53]$} \\
\hline \multirow[t]{5}{*}{$h$-BNNSs } & $\begin{array}{l}\text { Sonication-assisted } \\
\text { exfoliation }\end{array}$ & $\begin{array}{l}\text { It is a facile method to directly exfoliate BN bulk into HO-BNNSs } \\
\text { The hydroxyl degree is relatively low } \\
\text { For a high hydroxyl degree, some additives have to be introduced, such as, acid, } \\
\text { base, salt, etc }\end{array}$ & {$[31,55-63]$} \\
\hline & $\begin{array}{l}\text { Ball-milling-assisted } \\
\text { exfoliation }\end{array}$ & Situations similar to "sonication-assisted exfoliation" & {$[64-72]$} \\
\hline & Hummer's-like routes & $\begin{array}{l}\text { The use of strong oxidants (i.e., } \mathrm{H}_{2} \mathrm{SO}_{4}, \mathrm{H}_{2} \mathrm{O}_{2}, \mathrm{KMnO}_{4} \text {, and their mixtures) } \\
\text { requires an extra attention } \\
\text { Sometimes the oxidization process can lead to the presence of a few by-products } \\
\text { of } \mathrm{BN} \text { dots }\end{array}$ & {$[73-76]$} \\
\hline & $\begin{array}{l}\text { Multi-step } \\
\text { functionalization } \\
\text { method }\end{array}$ & $\begin{array}{l}\text { It can be divided into two stages: one is from } \mathrm{BN} \text { to BNNS and then to HO- } \\
\text { BNNS, the other is from BN to HO-BN and then to HO-BNNS }\end{array}$ & [82-92] \\
\hline & Bottom-up routes & It generally requires high temperatures and pressures & {$[93-98]$} \\
\hline \multirow[t]{2}{*}{ BNNTs } & In situ hydroxylation & Hydroxylated BNNTs can be directly obtained via a bottom-up approach & {$[111,112]$} \\
\hline & Treatment in $\mathrm{H}_{2} \mathrm{O}_{2}$ & $\begin{array}{l}\text { It is generally carried out by hydrothermal route and it does not require further } \\
\text { purification }\end{array}$ & {$[33,113-116]$} \\
\hline
\end{tabular}


Table 2 continued

\begin{tabular}{llll}
\hline BN materials & Methods & Evaluation & Refs \\
\hline $\begin{array}{l}\text { Treatment in acidic or } \\
\text { alkaline solution }\end{array}$ & It needs thermal post-treatment & {$[117,118]$} \\
$\begin{array}{l}\text { Other routes } \\
\text { Unconventional strategies are employed for surfaces modifications by } \mathrm{OH}_{\text {and }} \mathrm{NH}_{2}\end{array} \quad[119,120]$ & groups. Accurate $\mathrm{pH}$ control is often required \\
\hline
\end{tabular}

(iv) The optical properties modification and tuning, e.g., UV-Vis absorption, fluorescence, and NLO;

(v) The possibility to support catalysts, electrodes, etc.

Despite the great efforts that have been made, there are still many challenging phenomena to address and basic studies to perform. The hydroxylation process of BNs is still far from being well understood. Although it is predicted that $\mathrm{OH}$ groups can attach to both $\mathrm{B}$ and $\mathrm{N}$ sites, there are few experimental reports detecting the presence of $\mathrm{N}-\mathrm{OH}$ in $\mathrm{BN}$ systems. Thus, it remains an unanswered question whether $\mathrm{N}-\mathrm{OH}$ can depict a scenario other than B$\mathrm{OH}$. On the other hand, $\mathrm{OH}$ can be introduced on both surface and edges (armchair and zigzag) of BNNSs, but it is still difficult to appreciate or measure the differences in terms of properties. Furthermore, it is not yet clear which of the $\mathrm{OH}$ sites, whether on the surface or on edge, has the greatest influence on the functional properties.

As we know, hydroxyl groups usually are unstable under a thermal process. The thermal stability of nanomaterials and nanocomposites based on hydro$\mathrm{xyl}$ functionalized $\mathrm{BN}$ materials has, therefore, to be critically evaluated. For instance, the hydroxylation can enhance the filter capacity of BN-membrane. How about its filtering capability after going through a high-temperature process? The same question should also be considered about hydroxyl BN-based thermal conductors, energy storages, activators, mechanical materials, etc.

Although some works show that hydroxyl BN nanomaterials display low or non-toxicity in in vitro experimental results, it should be noted that their toxicity largely depends on the cellular systems, the concentrations, and sizes of BNs. Therefore, it is still important to verify the toxicity for more cell types and carry out more in vivo investigations in the future.
Significant results on HO-BNs systems have been accomplished. However, more theoretical and experimental efforts should be devoted to understand the mechanism through which the $\mathrm{OH}$ groups contribute to affect the functional properties. Another important direction of research is to develop advanced technologies using a property-tailored design of hydroxylated BN-based systems. In all mentioned fields, a feasible route is necessary to translate the laboratory findings into commercial engineering, supporting large-scale synthesis of highquality hydroxylated BN materials.

\section{Acknowledgements}

This work was supported by Fondi liberi di Ateneo 2019. L. S. gratefully acknowledges for the financial support "Programma Operativo Nazionale (PON) Ricerca e Innovazione 2014-2020- Linea 1".

\section{Funding}

Open access funding provided by Università degli Studi di Sassari within the CRUI-CARE Agreement..

\section{Compliance with ethical standards}

Conflict of interest The authors declare that they have no conflict of interest.

Open Access This article is licensed under a Creative Commons Attribution 4.0 International License, which permits use, sharing, adaptation, distribution and reproduction in any medium or format, as long as you give appropriate credit to the original author(s) and the source, provide a link to the Creative Commons licence, and indicate if changes were made. The images or other third party material in this article are included in the article's Creative Commons 
licence, unless indicated otherwise in a credit line to the material. If material is not included in the article's Creative Commons licence and your intended use is not permitted by statutory regulation or exceeds the permitted use, you will need to obtain permission directly from the copyright holder. To view a copy of this licence, visit http://creativecommons.org/licen ses/by $/ 4.0 /$.

\section{References}

[1] Weng Q, Wang X, Wang X, Bando Y, Golberg D (2016) Functionalized hexagonal boron nitride nanomaterials: emerging properties and applications. Chem Soc Rev 45:3989-4012. https://doi.org/10.1039/C5CS00869G

[2] Stagi L, Ren J, Innocenzi P (2019) From 2-D to 0-D boron nitride materials, the next challenge. Materials 12:3905. $\mathrm{h}$ ttps://doi.org/10.3390/ma12233905

[3] Caldwell JD, Aharonovich I, Cassabois G, Edgar JH, Gil B, Basov D (2019) Photonics with hexagonal boron nitride. Nat Rev Mater 4:552-567. https://doi.org/10.1038/s41578019-0124-1

[4] Zhang K, Feng Y, Wang F, Yang Z, Wang J (2017) Two dimensional hexagonal boron nitride (2D-hBN): synthesis, properties and applications. $\mathrm{J}$ Mater Chem C 5:11992-12022. https://doi.org/10.1039/C7TC04300G

[5] Xiong J, Di J, Zhu W, Li H (2020) Hexagonal boron nitride adsorbent: Synthesis, performance tailoring and applications. J Energy Chem 40:99-111. https://doi.org/10.1016/j. jechem.2019.03.002

[6] Ren J, Malfatti L, Enzo S, Carbonaro CM, Calvillo L, Granozzi G, Innocenzi P (2020) Boron oxynitride twocolour fluorescent dots and their incorporation in a hybrid organic-inorganic film. J Colloid Interface Sci 560:398-406. https://doi.org/10.1016/j.jcis.2019.10.020

[7] Watanabe K, Taniguchi T, Kanda H (2004) Direct-bandgap properties and evidence for ultraviolet lasing of hexagonal boron nitride single crystal. Nat Mater 3:404-409. https://d oi.org/10.1038/nmat1134

[8] Cassabois G, Valvin P, Gil B (2016) Hexagonal boron nitride is an indirect bandgap semiconductor. Nat Photonics 10:262-266. https://doi.org/10.1038/nphoton.2015.277

[9] Yu S, Wang X, Pang H, Zhang R, Song W, Fu D, Hayat T, Wang X (2018) Boron nitride-based materials for the removal of pollutants from aqueous solutions: a review. Chem Eng J 333:343-360. https://doi.org/10.1016/j.cej.20 17.09.163

[10] Ihsanullah I (2021) Boron nitride-based materials for water purification: progress and outlook. Chemosphere
263:127970. https://doi.org/10.1016/j.chemosphere.2020. 127970

[11] Lin Y, Williams TV, Connell JW (2010) Soluble, exfoliated hexagonal boron nitride nanosheets. J Phys Chem Lett 1:277-283. https://doi.org/10.1021/jz9002108

[12] Sinitskii A, Erickson KJ, Lu W, Gibb AL, Zhi C, Bando Y, Golberg D, Zettl A, Tour JM (2014) High-yield synthesis of boron nitride nanoribbons via longitudinal splitting of boron nitride nanotubes by potassium vapor. ACS Nano 8:9867-9873. https://doi.org/10.1021/nn504809n

[13] Smith MW, Jordan KC, Park C, Kim JW, Lillehei PT, Crooks R, Harrison JS (2009) Very long single-and fewwalled boron nitride nanotubes via the pressurized vapor/condenser method. Nanotechnology 20:505604. htt ps://doi.org/10.1088/0957-4484/20/50/505604

[14] Kim SS, Van Khai T, Kwon YJ, Katoch A, Wu P, Kim HW (2015) One-pot synthesis of h-BN fullerenes usinsg a graphene oxide template. Met Mater Int 21:950-955. https://d oi.org/10.1007/s12540-015-5043-0

[15] Watanabe K, Taniguchi T, Niiyama T, Miya K, Taniguchi M (2009) Far-ultraviolet plane-emission handheld device based on hexagonal boron nitride. Nat Photonics 3:591-594. https://doi.org/10.1038/nphoton.2009.167

[16] Hong S, Lee C-S, Lee MH, Lee Y, Ma KY, Kim G, Yoon SI, Ihm K, Kim KJ, Shin TJ (2020) Ultralow-dielectricconstant amorphous boron nitride. Nature 582:511-514. h ttps://doi.org/10.1038/s41586-020-2375-9

[17] Tran TT, Bray K, Ford MJ, Toth M, Aharonovich I (2016) Quantum emission from hexagonal boron nitride monolayers. Nat Nanotech 11:37-41. https://doi.org/10.1038/nna no.2015.242

[18] Hayee F, Yu L, Zhang JL, Ciccarino CJ, Nguyen M, Marshall AF, Aharonovich I, Vučković J, Narang P, Heinz TF (2020) Revealing multiple classes of stable quantum emitters in hexagonal boron nitride with correlated optical and electron microscopy. Nat Mater 19:534-539. https://d oi.org/10.1038/s41563-020-0616-9

[19] Zeng H, Zhi C, Zhang Z, Wei X, Wang X, Guo W, Bando Y, Golberg D (2010) “White graphenes": boron nitride nanoribbons via boron nitride nanotube unwrapping. Nano Lett 10:5049-5055. https://doi.org/10.1021/n1103251m

[20] Yang Y, Liu X, Zhu Z, Zhong Y, Bando Y, Golberg D, Yao J, Wang X (2018) The role of geometric sites in 2D materials for energy storage. Joule 2:1075-1094. https://d oi.org/10.1016/j.joule.2018.04.027

[21] Zhou H, Zhu J, Liu Z, Yan Z, Fan X, Lin J, Wang G, Yan Q, Yu T, Ajayan PM (2014) High thermal conductivity of suspended few-layer hexagonal boron nitride sheets. Nano Res 7:1232-1240. https://doi.org/10.1007/s12274-014-048 $6-\mathrm{Z}$ 
[22] Swain SK, Dash S, Behera C, Kisku SK, Behera L (2013) Cellulose nanobiocomposites with reinforcement of boron nitride: Study of thermal, oxygen barrier and chemical resistant properties. Carbohydr Polym 95:728-732. http s://doi.org/10.1016/j.carbpol.2013.02.080

[23] Lei W, Portehault D, Liu D, Qin S, Chen Y (2013) Porous boron nitride nanosheets for effective water cleaning. Nat Commun 4:1777. https://doi.org/10.1038/ncomms2818

[24] Cho H, Kim JH, Hwang JH, Kim CS, Jang SG, Park C, Lee H, Kim MJ (2020) Single- and double-walled boron nitride nanotubes: controlled synthesis and application for water purification. Sci Rep 10:7416. https://doi.org/10.1038/s41 598-020-64096-Z

[25] Qin D, Zhou Y, Wang W, Zhang C, Zeng G, Huang D, Wang L, Wang H, Yang Y, Lei L, Chen S, He D (2020) Recent advances in two-dimensional nanomaterials for photocatalytic reduction of $\mathrm{CO}_{2}$ : insights into performance, theories and perspective. J Mater Chem A 8:19156-19195. https://doi.org/10.1039/D0TA07460H

[26] Ciofani G, Raffa V, Menciassi A, Cuschieri A (2009) Boron nitride nanotubes: an innovative tool for nanomedicine. Nano Today 4:8-10. https://doi.org/10.1016/j.nantod.2008. 09.001

[27] Pan D, Su F, Liu H, Ma Y, Das R, Hu Q, Liu C, Guo Z (2020) The properties and preparation methods of different boron nitride nanostructures and applications of related nanocomposites. Chem Rec. https://doi.org/10.1002/tcr. 202000079

[28] Zheng Z, Cox M, Li B (2018) Surface modification of hexagonal boron nitride nanomaterials: a review. J Mater Sci 53:66-99. https://doi.org/10.1007/s10853-017-1472-0

[29] Emanet M, Sen Ö, Taşkin IÇ, Çulha M (2019) Synthesis, functionalization, and bioapplications of two-dimensional boron nitride nanomaterials. Front Bioeng Biotechnol. h ttps://doi.org/10.3389/fbioe.2019.00363

[30] Yu B, Xing W, Guo W, Qiu S, Wang X, Lo S, Hu Y (2016) Thermal exfoliation of hexagonal boron nitride for effective enhancements on thermal stability, flame retardancy and smoke suppression of epoxy resin nanocomposites via solgel process. J Mater Chem A 4:7330-7340. https://doi.org/ 10.1039/C6TA01565D

[31] Lin Y, Williams TV, Xu T-B, Cao W, Elsayed-Ali HE, Connell JW (2011) Aqueous dispersions of few-layered and monolayered hexagonal boron nitride nanosheets from sonication-assisted hydrolysis: critical role of water. J Phys Chem C 115:2679-2685. https://doi.org/10.1021/ jp110985w

[32] Wu K, Lei C, Yang W, Chai S, Chen F, Fu Q (2016) Surface modification of boron nitride by reduced graphene oxide for preparation of dielectric material with enhanced dielectric constant and well-suppressed dielectric loss. Compos Sci Technol 134:191-200. https://doi.org/10.1016/ j.compscitech.2016.08.015

[33] Zhi C, Bando Y, Terao T, Tang C, Kuwahara H, Golberg D (2009) Chemically activated boron nitride nanotubes. Chem Asian J 4:1536-1540. https://doi.org/10.1002/asia. 200900158

[34] Jiang Y, Liu Y, Min P, Sui G (2017) BN@PPS core-shell structure particles and their 3D segregated architecture composites with high thermal conductivities. Compos Sci Technol 144:63-69. https://doi.org/10.1016/j.compscitech. 2017.03.023

[35] Jiang X, Ma P, You F, Yao C, Yao J, Liu F (2018) A facile strategy for modifying boron nitride and enhancing its effect on the thermal conductivity of polypropylene/polystyrene blends. RSC Adv 8:32132-32137. https://doi.org/ 10.1039/C8RA06140H

[36] Lee J-H, Shin H, Rhee KY (2019) Surface functionalization of boron nitride platelets via a catalytic oxidation/silanization process and thermomechanical properties of boron nitride-epoxy composites. Compos Part B Eng 157:276-282. https://doi.org/10.1016/j.compositesb.2018.0 8.050

[37] He J, Liu S, Li Y, Zeng S, Qi Y, Cui L, Dai Q, Bai C (2019) Fabrication of boron nitride nanosheet/polymer composites with tunable thermal insulating properties. New J Chem 43:4878-4885. https://doi.org/10.1039/C8NJ06236F

[38] Yang N, Xu C, Hou J, Yao Y, Zhang Q, Grami ME, He L, Wang N, Qu X (2016) Preparation and properties of thermally conductive polyimide/boron nitride composites. RSC Adv 6:18279-18287. https://doi.org/10.1039/ C6RA01084A

[39] Kim K, Kim M, Hwang Y, Kim J (2014) Chemically modified boron nitride-epoxy terminated dimethylsiloxane composite for improving the thermal conductivity. Ceram Int 40:2047-2056. https://doi.org/10.1016/j.ceramint.2013. 07.117

[40] Kim K, Kim J (2014) Fabrication of thermally conductive composite with surface modified boron nitride by epoxy wetting method. Ceram Int 40:5181-5189. https://doi.org/ 10.1016/j.ceramint.2013.10.076

[41] Kim K, Kim M, Kim J (2014) Fabrication of UV-curable polyurethane acrylate composites containing surface-modified boron nitride for underwater sonar encapsulant application. Ceram Int 40:10933-10943. https://doi.org/10.1016/ j.ceramint.2014.03.092

[42] Wang X, Ji S, Wang X, Bian H, Lin L, Dai H, Xiao H (2019) Thermally conductive, super flexible and flame-retardant $\mathrm{BN}-\mathrm{OH} / \mathrm{PVA}$ composite film reinforced by lignin 
nanoparticles. J Mater Chem C 7:14159-14169. https://doi. org/10.1039/C9TC04961D

[43] Rathod NH, Yadav V, Rajput A, Sharma J, Shukla D, Kulshrestha V (2020) New class of composite anion exchange membranes based on Quaternized poly (phenylene oxide) and functionalized boron nitride. Colloids Interface Sci Commun 36:100265. https://doi.org/10.1016/ j.colcom.2020.100265

[44] Xie B, Huang X, Zhang G (2013) High thermal conductive polyvinyl alcohol composites with hexagonal boron nitride microplatelets as fillers. Compos Sci Technol 85:98-103. h ttps://doi.org/10.1016/j.compscitech.2013.06.010

[45] Yadav V, Rajput A, Rathod NH, Kulshrestha V (2020) Enhancement in proton conductivity and methanol crossover resistance by sulfonated boron nitride composite sulfonated poly (ether ether ketone) proton exchange membrane. Int J Hydrog Energy 45:17017-17028. https://doi. org/10.1016/j.ijhydene.2019.06.091

[46] An D, Cheng S, Jiang C, Duan X, Yang B, Zhang Z, Li J, Liu Y, Wong CP (2020) A novel environmentally friendly boron nitride/lignosulfonate/natural rubber composite with improved thermal conductivity. J Mater Chem C 8:4801-4809. https://doi.org/10.1039/C9TC05699H

[47] Feng Y, Zhou Y, Lee P-H, Shih K (2016) Mineralization of perfluorooctanesulfonate (PFOS) and perfluorodecanoate (PFDA) from aqueous solution by porous hexagonal boron nitride: adsorption followed by simultaneous thermal decomposition and regeneration. RSC Adv 6:113773-113780. https://doi.org/10.1039/C6RA15564B

[48] Kostoglou N, Lukovic J, Babic B, Matovic B, Photiou D, Constantinides G, Polychronopoulou K, Ryzhkov V, Grossmann B, Mitterer C (2016) Few-step synthesis, thermal purification and structural characterization of porous boron nitride nanoplatelets. Mater Des 110:540-548. http s://doi.org/10.1016/j.matdes.2016.08.011

[49] Zhao Y, Liu Z, Cao C, Wang C, Fang Y, Huang Y, Yu C, Zhang J, Li L, Hu L (2017) Self-sacrificed template synthesis of ribbon-like hexagonal boron nitride nano-architectures and their improvement on mechanical and thermal properties of PHA polymer. Sci Rep 7:9006. https://doi.org/ 10.1038/s41598-017-08524-7

[50] Song Q, Fang Y, Liu Z, Li L, Wang Y, Liang J, Huang Y, Lin J, Hu L, Zhang J (2017) The performance of porous hexagonal $\mathrm{BN}$ in high adsorption capacity towards antibiotics pollutants from aqueous solution. Chem Eng J 325:71-79. https://doi.org/10.1016/j.cej.2017.05.057

[51] Wu P, Lu L, He J, Chen L, Chao Y, He M, Zhu F, Chu X, Li H, Zhu W (2020) Hexagonal boron nitride: a metal-free catalyst for deep oxidative desulfurization of fuel oils.
Green Energy Environ 5:166-172. https://doi.org/10.1016/ j.gee.2020.03.004

[52] Li J, Huang Y, Liu Z, Zhang J, Liu X, Luo H, Ma Y, Xu X, Lu Y, Lin J (2015) Chemical activation of boron nitride fibers for improved cationic dye removal performance. J Mater Chem A 3:8185-8193. https://doi.org/10.1039/ C5TA00601E

[53] Shi L, Wang D, Song W, Shao D, Zhang WP, Lu AH (2017) Edge-hydroxylated boron nitride for oxidative dehydrogenation of propane to propylene. ChemCatChem 9:1788-1793. https://doi.org/10.1002/cctc.201700745

[54] Cui Z, Oyer AJ, Glover AJ, Schniepp HC, Adamson DH (2014) Large scale thermal exfoliation and functionalization of boron nitride. Small 10:2352-2355. https://doi.org/ $10.1002 / \mathrm{smll} .201303236$

[55] Tang Y, Lin D, Gao Y, Xu J, Guo B (2014) Prominent nucleating effect of finely dispersed hydroxyl-functional hexagonal boron nitride on biodegradable poly (butylene succinate). Ind Eng Chem Res 53:4689-4696. https://doi. org/10.1021/ie403915j

[56] Roy AK, Park B, Lee KS, Park SY, In I (2014) Boron nitride nanosheets decorated with silver nanoparticles through mussel-inspired chemistry of dopamine. Nanotechnology 25:445603. https://doi.org/10.1088/0957-448 $4 / 25 / 44 / 445603$

[57] Kim TY, Song EH, Kang BH, Kim SJ, Lee Y-H, Ju B-K (2017) Hydrolyzed hexagonal boron nitride/polymer nanocomposites for transparent gas barrier film. Nanotechnology 28:12LT01. https://doi.org/10.1088/1361-652 8/aa5f2e

[58] Ren J, Stagi L, Carbonaro CM, Malfatti L, Casula MF, Ricci PC, Rio AD, Bonaccorso F, Calvillo L, Granozzi G, Innocenzi P (2020) Defect-assisted photoluminescence in hexagonal boron nitride nanosheets. 2D Mater 7:045023. $\mathrm{h}$ ttps://doi.org/10.1088/2053-1583/ababf0

[59] Dorn RW, Ryan MJ, Kim TH, Goh TW, Venkatesh A, Heintz PM, Zhou L, Huang W, Rossini AJ (2020) Identifying the molecular edge termination of exfoliated hexagonal boron nitride nanosheets with solid-state NMR spectroscopy and plane-wave DFT calculations. Chem Mater 32:3109-3121. https://doi.org/10.1021/acs.chemmat er.0c00104

[60] Rosely CS, Shaiju P, Gowd EB (2019) Poly (l-lactic acid)/ boron nitride nanocomposites: influence of boron nitride functionalization on the properties of poly (l-lactic acid). J Phys Chem B 123:8599-8609. https://doi.org/10.1021/ac s.jpcb.9b07743

[61] Fu L, Lai G, Chen G, Lin CT, Yu A (2016) Microwave irradiation-assisted exfoliation of boron nitride nanosheets: a platform for loading high density of nanoparticles. 
ChemistrySelect 1:1799-1803. https://doi.org/10.1002/slct. 201600290

[62] Jiang F, Cui S, Song N, Shi L, Ding P (2018) Hydrogen bond-regulated boron nitride network structures for improved thermal conductive property of polyamide-imide composites. ACS Appl Mater Interfaces 10:16812-16821. https://doi.org/10.1021/acsami.8b03522

[63] Deshmukh AR, Jeong JW, Lee SJ, Park GU, Kim BS (2019) Ultrasound-assisted facile green synthesis of hexagonal boron nitride nanosheets and their applications. ACS Sustain Chem Eng 7:17114-17125. https://doi.org/10. 1021/acssuschemeng.9b03387

[64] Lee D, Lee B, Park KH, Ryu HJ, Jeon S, Hong SH (2015) Scalable exfoliation process for highly soluble boron nitride nanoplatelets by hydroxide-assisted ball milling. Nano Lett 15:1238-1244. https://doi.org/10.1021/n1504397h

[65] Kwon OS, Lee D, Lee SP, Kang YG, Kim NC, Song SH (2016) Enhancing the mechanical and thermal properties of boron nitride nanoplatelets/elastomer nanocomposites by latex mixing. RSC Adv 6:59970-59975. https://doi.org/10. 1039/C6RA11356G

[66] Lee D, Lee S, Byun S, Paik KW, Song SH (2018) Novel dielectric BN/epoxy nanocomposites with enhanced heat dissipation performance for electronic packaging. Compos Part A Appl Sci Manuf 107:217. https://doi.org/10.1016/j.c ompositesa.2018.01.009

[67] Liu B, Yan S, Zhang A, Song Z, Sun Q, Huo B, Yang W, Barrow CJ, Liu J (2019) Insight into catalytic mechanisms for the reduction of nitrophenol via heterojunctions of gold nanoclusters on 2D boron nitride nanosheets. ChemNanoMat 5:784-791. https://doi.org/10.1002/cnma.201900126

[68] Fan D, Feng J, Liu J, Gao T, Ye Z, Chen M, Lv X (2016) Hexagonal boron nitride nanosheets exfoliated by sodium hypochlorite ball mill and their potential application in catalysis. Ceram Int 42:7155-7163. https://doi.org/10.1016/ j.ceramint.2016.01.105

[69] Wang Y, Low Z, Kim S, Zhang H, Chen X, Hou J, Seong JG, Lee YM, Simon GP, Davies CHJ, Wang H (2018) Functionalized boron nitride nanosheets: a thermally rearranged polymer nanocomposite membrane for hydrogen separation. Angew Chem Int Ed 57:16056-16061. https://d oi.org/10.1002/ange.201809126

[70] Wu L, Luo N, Xie Z, Liu Y, Chen F, Fu Q (2020) Improved breakdown strength of poly (vinylidene fluoride)-based composites by using all ball-milled hexagonal boron nitride sheets without centrifugation. Compos Sci Technol 190:108046. https://doi.org/10.1016/j.compscitech.2020. 108046

[71] Cao C, Xue Y, Liu Z, Zhou Z, Ji J, Song Q, Hu Q, Fang Y, Tang C (2019) Scalable exfoliation and gradable separation of boric-acid-functionalized boron nitride nanosheets. 2D Mater 6:035014. https://doi.org/10.1088/2053-1583/ab0eb4

[72] Ji D, Wang Z, Zhu Y, Yu H (2020) One-step environmentally friendly exfoliation and functionalization of hexagonal boron nitride by $\beta$-cyclodextrin-assisted ball milling. Ceram Int 46:21084-21089. https://doi.org/10.1016/j.cera mint.2020.05.181

[73] Bhimanapati GR, Kozuch D, Robinson JA (2014) Largescale synthesis and functionalization of hexagonal boron nitride nanosheets. Nanoscale 6:11671-11675. https:/doi. org/10.1039/C4NR01816H

[74] Jing L, Li H, Tay RY, Sun B, Tsang SH, Cometto O, Lin J, Teo EHT, Tok AIY (2017) Biocompatible hydroxylated boron nitride nanosheets/poly (vinyl alcohol) interpenetrating hydrogels with enhanced mechanical and thermal responses. ACS Nano 11:3742-3751. https://doi.org/10.10 21/acsnano.6b08408

[75] Czarniewska E, Mrówczyńska L, Jędrzejczak-Silicka M, Nowicki P, Trukawka M, Mijowska E (2019) Non-cytotoxic hydroxyl-functionalized exfoliated boron nitride nanoflakes impair the immunological function of insect haemocytes in vivo. Sci Rep 9:14027. https://doi.org/10. 1038/s41598-019-50097-0

[76] Zhang W, Rahman MM, Ahmed F, Lopa NS, Ge C, Ryu T, Yoon S, Jin L, Jang H, Kim W (2020) A two-step approach for improved exfoliation and cutting of boron nitride into boron nitride nanodisks with covalent functionalizations. Nanotechnology 31:425604. https://doi.org/10.1088/13616528/ab9a76/meta

[77] Guo F, Shen X, Zhou J, Liu D, Zheng Q, Yang J, Jia B, Lau AK, Kim JK (2020) Highly thermally conductive dielectric nanocomposites with synergistic alignments of graphene and boron nitride nanosheets. Adv Funct Mater 30:1910826. https://doi.org/10.1002/adfm.201910826

[78] Zhao G, Zhang F, Wu Y, Hao X, Wang Z, Xu X (2016) One-step exfoliation and hydroxylation of boron nitride nanosheets with enhanced optical limiting performance. Adv Opt Mater 4:141-146. https://doi.org/10.1002/adom. 201500415

[79] Wang N, Yang G, Wang H, Yan C, Sun R, Wong CP (2019) A universal method for large-yield and high-concentration exfoliation of two-dimensional hexagonal boron nitride nanosheets. Mater Today 27:33-42. https://doi.org/10.101 6/j.mattod.2018.10.039

[80] Xiao F, Naficy S, Casillas G, Khan MH, Katkus T, Jiang L, Liu H, Li H, Huang Z (2015) Edge-hydroxylated boron nitride nanosheets as an effective additive to improve the thermal response of hydrogels. Adv Mater 27:7196-7203. h ttps://doi.org/10.1002/adma.201502803 
[81] Shi X, Wang K, Tian J, Yin X, Guo B, Xi G, Wang W, Wu W (2020) Few-layer hydroxyl-functionalized boron nitride nanosheets for nanoscale thermal management. ACS Appl Nano Mater 3:2310-2321. https://doi.org/10.1021/acsanm. $9 \mathrm{~b} 02427$

[82] Sainsbury T, Satti A, May P, Wang Z, McGovern I, Gun'ko YK, Coleman J (2012) Oxygen radical functionalization of boron nitride nanosheets. J Am Chem Soc 134:18758-18771. https://doi.org/10.1021/ja3080665

[83] Kumari S, Sharma OP, Gusain R, Mungse HP, Kukrety A, Kumar N, Sugimura H, Khatri OP (2015) Alkyl-chaingrafted hexagonal boron nitride nanoplatelets as oil-dispersible additives for friction and wear reduction. ACS Appl Mater Interfaces 7:3708-3716. https://doi.org/10.102 1/am5083232

[84] Nurunnabi M, Nafiujjaman M, Lee SJ, Park IK, Huh KM, Lee YK (2016) Preparation of ultra-thin hexagonal boron nitride nanoplates for cancer cell imaging and neurotransmitter sensing. Chem Commun 52:6146-6149. https://doi. org/10.1039/C5CC10650H

[85] Salehirad M, Nikje MMA (2017) Synthesis and characterization of exfoliated polystyrene grafted hexagonal boron nitride nanosheets and their potential application in heat transfer nanofluids. Iran Polym J 26:467-480. https://doi. org/10.1007/s13726-017-0535-Z

[86] Yang W, Wang N, Ping P, Yuen ACY, Li A, Zhu SE, Wang L, Wu J, Chen TBY, Si J (2018) Novel 3D network architectured hybrid aerogel comprising epoxy, graphene, and hydroxylated boron nitride nanosheets. ACS Appl Mater Interfaces 10:40032-40043. https://doi.org/10.1021/ acsami.8b15301

[87] Wu L, Wu K, Liu D, Huang R, Huo J, Chen F, Fu Q (2018) Largely enhanced energy storage density of poly (vinylidene fluoride) nanocomposites based on surface hydroxylation of boron nitride nanosheets. J Mater Chem A 6:7573-7584. https://doi.org/10.1039/C8TA01294F

[88] Wu L, Wu K, Lei C, Liu D, Du R, Chen F, Fu Q (2019) Surface modifications of boron nitride nanosheets for poly (vinylidene fluoride) based film capacitors: advantages of edge-hydroxylation. J Mater Chem A 7:7664-7674. http s://doi.org/10.1039/C9TA00616H

[89] Fu L, Wang T, Yu J, Dai W, Sun H, Liu Z, Sun R, Jiang N, Yu A, Lin C (2017) An ultrathin high-performance heat spreader fabricated with hydroxylated boron nitride nanosheets. 2D Mater 4:025047. https://doi.org/10.1088/2 053-1583/aa636e

[90] Zhao H, Ding J, Yu H (2018) Phosphorylated boron nitride nanosheets as highly effective barrier property enhancers. Ind Eng Chem Res 57:14096-14105. https://doi.org/10.10 21/acs.iecr.8b03220
[91] Chen S, Xu R, Liu J, Zou X, Qiu L, Kang F, Liu B, Cheng HM (2019) Simultaneous production and functionalization of boron nitride nanosheets by sugar-assisted mechanochemical exfoliation. Adv Mater 31:1804810. h ttps://doi.org/10.1002/adma.201804810

[92] Xiao C, Guo Y, Tang Y, Ding J, Zhang X, Zheng K, Tian X (2020) Epoxy composite with significantly improved thermal conductivity by constructing a vertically aligned threedimensional network of silicon carbide nanowires/boron nitride nanosheets. Compos Part B Eng 187:107855. http s://doi.org/10.1016/j.compositesb.2020.107855

[93] Li LH, Xing T, Chen Y, Jones R (2014) Boron nitride nanosheets for metal protection. Adv Mater Interfaces 1:1300132. https://doi.org/10.1002/admi.201300132

[94] Singh B, Kaur G, Singh P, Singh K, Kumar B, Vij A, Kumar M, Bala R, Meena R, Singh A (2016) Nanostructured boron nitride with high water dispersibility for boron neutron capture therapy. Sci Rep 6:35535. https://doi.org/ 10.1038/srep35535

[95] Zhan Y, Yan J, Wu M, Guo L, Lin Z, Qiu B, Chen G, Wong KY (2017) Boron nitride nanosheets as a platform for fluorescence sensing. Talanta 174:365-371. https://doi.org/10. 1016/j.talanta.2017.06.032

[96] Cai W, Zhang D, Wang B, Shi Y, Pan Y, Wang J, Hu W, Hu Y (2018) Scalable one-step synthesis of hydroxylated boron nitride nanosheets for obtaining multifunctional polyvinyl alcohol nanocomposite films: Multi-azimuth properties improvement. Compos Sci Technol 168:74-80. h ttps://doi.org/10.1016/j.compscitech.2018.09.004

[97] Li T, Li C, Cai Y, Lin J, Long X, Wang L, Xu Y, Sun J, Tang L, Zhang Y (2018) Highly efficient mass production of boron nitride nanosheets via a borate nitridation method. J Phys Chem C 122:17370-17377. https://doi.org/10.1021 /acs.jpcc.8b05702

[98] Chao Y, Zhang J, Li H, Wu P, Li X, Chang H, He J, Wu H, Li H, Zhu W (2020) Synthesis of boron nitride nanosheets with N-defects for efficient tetracycline antibiotics adsorptive removal. Chem Eng J 387:124138. https://doi.org/10. 1016/j.cej.2020.124138

[99] Wang H, Liu Y, Wang H, Zhao J, Cai Q, Wang X (2013) Stability and properties of the two-dimensional hexagonal boron nitride monolayer functionalized by hydroxyl $(\mathrm{OH})$ radicals: a theoretical study. J Mol Model 19:5143-5152. h ttps://doi.org/10.1007/s00894-013-2013-7

[100] Guo Y, Guo W (2015) Hydroxylation of a metal-supported hexagonal boron nitride monolayer by oxygen induced water dissociation. Phys Chem Chem Phys 17:16428-16433. https://doi.org/10.1039/C5CP02494C

[101] Grosjean B, Pean C, Siria A, Bocquet L, Vuilleumier R, Bocquet ML (2016) Chemisorption of hydroxide on 2D 
materials from DFT calculations: graphene versus hexagonal boron nitride. J Phys Chem Lett 7:4695-4700. https://d oi.org/10.1021/acs.jpclett.6b02248

[102] Hosseini E, Zakertabrizi M, Habibnejad Korayem A, Chang Z (2018) Mechanical and electromechanical properties of functionalized hexagonal boron nitride nanosheet: A density functional theory study. J Chem Phys 149:114701. https://doi.org/10.1063/1.5043252

[103] Qin G, Wang W, Du A, Sun Q (2020) Functionalized boron nitride monolayers as promising materials for uranyl ion capture: A first-principles study. J Mol Struct 1200:127080. https://doi.org/10.1016/j.molstruc.2019.127080

[104] Sharma BB, Parashar A (2020) Mechanical and fracture behaviour of hydroxyl functionalized h-BN nanosheets. J Mater Sci 55:3228-3242. https://doi.org/10.1007/s10853019-04163-7

[105] Zhao J, Ding Y (2009) The effects of $\mathrm{O}_{2}$ and $\mathrm{H}_{2} \mathrm{O}$ adsorbates on field-emission properties of an $(8,0)$ boron nitride nanotube: a density functional theory study. Nanotechnology 20:085704. https://doi.org/10.1088/0957-4484/20/8/ 085704

[106] Anota EC, Cocoletzi GH (2013) First-principles simulations of the chemical functionalization of $(5,5)$ boron nitride nanotubes. J Mol Model 19:2335-2341. https://doi.org/10. 1007/s00894-013-1782-3

[107] Pakdel A, Bando Y, Golberg D (2014) Plasma-assisted interface engineering of boron nitride nanostructure films. ACS Nano 8:10631-10639. https://doi.org/10.1021/ nn5041729

[108] Duverger E, Gharbi T, Delabrousse E, Picaud F (2014) Quantum study of boron nitride nanotubes functionalized with anticancer molecules. Phys Chem Chem Phys 16:18425-18432. https://doi.org/10.1039/C4CP01660B

[109] El Khalifi M, Duverger E, Gharbi T, Boulahdour H, Picaud F (2016) Theoretical use of boron nitride nanotubes as a perfect container for anticancer molecules. Anal Methods 8:1367-1372. https://doi.org/10.1039/C5AY02822A

[110] Mortazavifar A, Raissi H, Akbari A (2019) DFT and MD investigations on the functionalized boron nitride nanotube as an effective drug delivery carrier for Carmustine anticancer drug. J Mol Liq 276:577-587. https://doi.org/10.10 16/j.molliq.2018.12.028

[111] Soares DCF, Ferreira TH, de Aguiar FC, Cardoso VN, de Sousa EMB (2012) Boron nitride nanotubes radiolabeled with ${ }^{99 \mathrm{~m}}$ Tc: Preparation, physicochemical characterization, biodistribution study, and scintigraphic imaging in Swiss mice. Int J Pharm 423:489-495. https://doi.org/10.1016/j. ijpharm.2011.12.002

[112] Guan J, Ashrafi B, Martinez-Rubi Y, Jakubinek MB, Rahmat M, Kim KS, Simard B (2018) Epoxy resin nanocomposites with hydroxyl $(\mathrm{OH})$ and amino $\left(\mathrm{NH}_{2}\right)$ functionalized boron nitride nanotubes. Nanocomposites 4:10-17. https://doi.org/10.1080/20550324.2018.1457764

[113] Emanet M, Şen Ö, Çobandede Z, Çulha M (2015) Interaction of carbohydrate modified boron nitride nanotubes with living cells. Colloids Surf B 134:440-446. https://doi. org/10.1016/j.colsurfb.2015.07.036

[114] Emanet M, Fakhrullin R, Çulha M (2016) Boron nitride nanotubes and layer-by-layer polyelectrolyte coating for yeast cell surface engineering. ChemNanoMat 2:426-429. https://doi.org/10.1002/cnma.201600044

[115] Şen Ö, Çobandede Z, Emanet M, Bayrak ÖF, Çulha M (2017) Boron nitride nanotubes for gene silencing. BBAGen Subjects 1861:2391-2397. https://doi.org/10.1016/j.b bagen.2017.05.026

[116] Wang W, Li Z, Prestat E, Hashimoto T, Guan J, Kim KS, Kingston CT, Simard B, Young RJ (2019) Reinforcement of polymer-based nanocomposites by thermally conductive and electrically insulating boron nitride nanotubes. ACS Appl Nano Mater 3:364-374. https://doi.org/10.1021/acsa nm.9b02010

[117] Ciofani G, Genchi GG, Liakos I, Athanassiou A, Dinucci D, Chiellini F, Mattoli V (2012) A simple approach to covalent functionalization of boron nitride nanotubes. J Colloid Interface Sci 374:308-314. https://doi.org/10.10 16/j.jcis.2012.01.049

[118] Zhang C, Huang R, Wang Y, Wu Z, Guo S, Zhang H, Li J, Huang C, Wang W, Li L (2018) Aminopropyltrimethoxysilane-functionalized boron nitride nanotube based epoxy nanocomposites with simultaneous high thermal conductivity and excellent electrical insulation. J Mater Chem A 6:20663-20668. https://doi.org/10.1039/ C8TA07435F

[119] Huang Q, Bando Y, Zhi C, Golberg D, Kurashima K, Xu F, Gao L (2006) Chemical peeling and branching of boron nitride nanotubes in dimethyl sulfoxide. Angew Chem Int Ed 45:2044-2047. https://doi.org/10.1002/anie.200504351

[120] Guan J, Kim KS, Jakubinek MB, Simard B (2018) pHswitchable water-soluble boron nitride nanotubes. ChemistrySelect 3:9308-9312. https://doi.org/10.1002/slct. 201801544

[121] Weng Q, Wang B, Wang X, Hanagata N, Li X, Liu D, Wang X, Jiang X, Bando Y, Golberg D (2014) Highly water-soluble, porous, and biocompatible boron nitrides for anticancer drug delivery. ACS Nano 8:6123-6130. https://d oi.org/10.1021/nn5014808

[122] Xue Y, Dai P, Jiang X, Wang X, Zhang C, Tang D, Weng Q, Wang X, Pakdel A, Tang C (2016) Template-free synthesis of boron nitride foam-like porous monoliths and their high- 
end applications in water purification. J Mater Chem A 4:1469-1478. https://doi.org/10.1039/C5TA08134C

[123] Li J, He S, Li R, Dai W, Tao J, Wang C, Liu J, Wu T, Tang C (2018) Template-free synthesis of three dimensional porous boron nitride nanosheets for efficient water cleaning. RSC Adv 8:32886-32892. https://doi.org/10.1039/ C8RA06445H

[124] Weng Q, Ide Y, Wang X, Wang X, Zhang C, Jiang X, Xue Y, Dai P, Komaguchi K, Bando Y (2015) Design of BN porous sheets with richly exposed (002) plane edges and their application as $\mathrm{TiO}_{2}$ visible light sensitizer. Nano Energy 16:19-27. https://doi.org/10.1016/j.nanoen.2015.0 6.004

[125] Liu Q, Chen C, Du M, Wu Y, Ren C, Ding K, Song M, Huang C (2018) Porous hexagonal boron nitride sheets: effect of hydroxyl and secondary amino groups on photocatalytic hydrogen evolution. ACS Appl Nano Mater 1:4566-4575. https://doi.org/10.1021/acsanm.8b00867

[126] Liu F, Yu J, Ji X, Qian M (2015) Nanosheet-structured boron nitride spheres with a versatile adsorption capacity for water cleaning. ACS Appl Mater Interfaces 7:1824-1832. https://doi.org/10.1021/am507491z

[127] Cao L, Dai P, Tang J, Li D, Chen R, Liu D, Gu X, Li L, Bando Y, Ok YS (2020) Spherical Superstructure of Boron Nitride Nanosheets Derived from Boron-Containing MetalOrganic Frameworks. J Am Chem Soc 142:8755-8762. h ttps://doi.org/10.1021/jacs.0c01023

[128] Han W, Wang L, Zhang R, Ge C, Ma Z, Yang Y, Zhang X (2017) Water-dispersible boron nitride nanospheres with high thermal conductivity for heat-transfer nanofluids. Eur J Inorg Chem 2017:5466-5474. https://doi.org/10.1002/ejic. 201700998
[129] Feng S, Zhang H, Yan T, Huang D, Zhi C, Nakanishi H, Gao X (2016) Folate-conjugated boron nitride nanospheres for targeted delivery of anticancer drugs. Int J Nanomedicine 11:4573. https://doi.org/10.2147/IJN.S110689

[130] Feng S, Zhang H, Zhi C, Gao X, Nakanishi H (2018) pHresponsive charge-reversal polymer-functionalized boron nitride nanospheres for intracellular doxorubicin delivery. Int J Nanomedicine 13:641. https://doi.org/10.2147/IJN. S153476

[131] Li X, Wang X, Zhang J, Hanagata N, Wang X, Weng Q, Ito A, Bando Y, Golberg D (2017) Hollow boron nitride nanospheres as boron reservoir for prostate cancer treatment. Nat Commun 8:13936. https://doi.org/10.1038/nc omms13936

[132] Tang C, Bando Y, Huang Y, Zhi C, Golberg D (2008) Synthetic routes and formation mechanisms of spherical boron nitride nanoparticles. Adv Funct Mater 18:3653-3661. https://doi.org/10.1002/adfm.200800493

[133] Xiong J, Yang L, Chao Y, Pang J, Zhang M, Zhu W, Li H (2016) Boron nitride mesoporous nanowires with doped oxygen atoms for the remarkable adsorption desulfurization performance from fuels. ACS Sustain Chem Eng 4:4457-4464. https://doi.org/10.1021/acssuschemeng.6b 01156

[134] Jalaly M, Gotor FJ, Semnan M, Sayagués MJ (2017) A novel, simple and rapid route to the synthesis of boron cabonitride nanosheets: combustive gaseous unfolding. Sci Rep 7:3453. https://doi.org/10.1038/s41598-017-03794-7

Publisher's Note Springer Nature remains neutral with regard to jurisdictional claims in published maps and institutional affiliations. 